\title{
Cardiomyocyte Hypertrophy in Arrhythmogenic Cardiomyopathy
}

Mustafa Gerçek, ${ }^{*}$ Muhammed Gerçek, ${ }^{*}$ Sebastian Kant, ${ }^{*}$ Sakine Simsekyilmaz, ${ }^{\dagger}$ Astrid Kassner, ${ }^{\ddagger}$ Hendrik Milting, Elisa A. Liehn, ${ }^{\S}$ Rudolf E. Leube, ${ }^{*}$ and Claudia A. Krusche*

From the Institutes for Molecular and Cellular Anatomy* and the Institute for Molecular Cardiovascular Research and Interdisciplinary Center for Clinical Research Aachen ${ }^{\S}$ Rheinisch-Westfälische Technische Hochschule Aachen University, Aachen; the Institute of Pharmacology and Clinical Pharmacology, ${ }^{\dagger}$ Heinrich Heine University, Düsseldorf; and the Heart and Diabetes Center North Rhine-Westphalia, ${ }^{\ddagger}$ Erich and Hanna Klessmann Institute for Cardiovascular Research and Development, Bad Oeynhausen, Germany

Accepted for publication December 20, 2016.

Address correspondence to Claudia A. Krusche, Ph.D., Institute for Molecular and Cellular Anatomy, RWTH Aachen University, Wendlingweg 2, 52074, Aachen, Germany. E-mail: ckrusche@ ukaachen.de.

\begin{abstract}
Arrhythmogenic cardiomyopathy $(A C)$ is a hereditary disease leading to sudden cardiac death or heart failure. AC pathology is characterized by cardiomyocyte loss and replacement fibrosis. Our goal was to determine whether cardiomyocytes respond to AC progression by pathological hypertrophy. To this end, we examined tissue samples from $A C$ patients with end-stage heart failure and tissue samples that were collected at different disease stages from desmoglein 2-mutant mice, a well characterized AC model. We find that cardiomyocyte diameters are significantly increased in right ventricles of AC patients. Increased mRNA expression of the cardiac stress marker natriuretic peptide $B$ is also observed in the right ventricle of $\mathrm{AC}$ patients. Elevated myosin heavy chain $7 \mathrm{mRNA}$ expression is detected in left ventricles. In desmoglein 2-mutant mice, cardiomyocyte diameters are normal during the concealed disease phase but increase significantly after acute disease onset on cardiomyocyte death and fibrotic myocardial remodeling. Hypertrophy progresses further during the chronic disease stage. In parallel, mRNA expression of myosin heavy chain 7 and natriuretic peptide $B$ is up-regulated in both ventricles with right ventricular preference. Calcineurin/nuclear factor of activated T cells (Nfat) signaling, which is linked to pathological hypertrophy, is observed during AC progression, as evidenced by Nfatc2 and Nfatc 3 mRNA in cardiomyocytes and increased mRNA of the Nfat target regulator of calcineurin 1. Taken together, we demonstrate that pathological hypertrophy occurs in $A C$ and is secondary to cardiomyocyte loss and cardiac remodeling. (Am J Pathol 2017, 187: 752-766; http://dx.doi.org/10.1016/j.ajpath.2016.12.018)
\end{abstract}

Arrhythmogenic right ventricular cardiomyopathy, which is now referred to as arrhythmogenic cardiomyopathy (AC), ${ }^{1}$ is an inherited disease with mutations in genes encoding the desmosomal proteins desmoglein 2, desmocollin 2, plakophilin 2 , plakoglobin, and desmoplakin, ${ }^{2}$ as well as genes encoding titin, desmin, phospholamban, ryanodine receptor 2 , transmembrane protein 43 , lamin $\mathrm{A} / \mathrm{C}, \alpha \mathrm{T}$-catenin, and transforming growth factor- $\beta 3{ }^{3}$ It has a prevalence of $1: 2,000$ to $1: 5,000 .{ }^{4} \mathrm{AC}$ patients experience arrhythmia with an increased risk of sudden cardiac death. Dilation and thinning of the right ventricle are typically observed, ${ }^{3}$ but a biventricular involvement has also been reported in $52 \%$ to $76 \%$ of AC patients. ${ }^{5,6}$ Occasionally, atria are also affected at late disease stages. ${ }^{5,7} \mathrm{AC}$ onset occurs usually in young adults between 20 and 40 years old. ${ }^{8}$ In severe cases, the onset is already observed in children at the beginning of puberty (10 to 12 years old). In contrast, disease manifestation in patients with fewer pathogenic mutations may occur only in old age ( $>60$ years $\left.{ }^{9}\right)$. Intense physical activity enhances biventricular disease progression, increases the risk for life-threatening arrhythmia, and shortens the time between disease onset and development of heart failure. ${ }^{10,11}$

The following phases can be distinguished during AC disease progression $^{8}:$ i) The concealed preclinical phase with

Supported by the Interdisciplinary Center for Clinical Research Aachen within the Faculty of Medicine at Rheinisch-Westfälische Technische Hochschule Aachen University (research group to E.A.L.) and by the Interdisciplinary Center for Clinical Research within the Faculty of Medicine at Rheinisch-Westfälische Technische Hochschule Aachen University grants T9-2 and K7-4 (R.E.L. and C.A.K.).

Disclosures: None declared. 
a risk of life-threatening arrhythmia: Minor arrhythmias may or may not occur. Structural cardiac abnormalities are absent. ii) The phase of overt electrical disorders: Ventricular arrhythmias are detectable. Functional and structural abnormalities of the right ventricle are noted. iii) The phase of heart failure: Biventricular pump failure develops.

$\mathrm{AC}$ disease manifestation is histologically characterized by a replacement of the necrotic right ventricular myocardium with fibrous and adipose tissue. ${ }^{12}$ In case of left ventricular involvement, the fibrous tissue replacement predominantly takes place within the lateral and posterior walls. ${ }^{3,13}$ In severe cases of childhood AC, extensive infarction-like fibrous scars develop on cardiomyocyte loss. ${ }^{14,15}$ Another prominent histological feature of $\mathrm{AC}$ is a transient immune cell invasion into the diseased myocardium, which correlates with the extent of necrotic lesion formation. ${ }^{7}$

A common and ubiquitous hallmark feature of cardiomyopathy is the cardiomyocyte hypertrophy, which has not been investigated in detail during AC disease progression. Cardiomyocyte hypertrophy is a reactive response to intrinsic and/or extrinsic mechanical stress to maintain cardiac function. Physiological hypertrophy occurs during heart development and growth. It is linked to an increase in heart weight. Reactive, reversible hypertrophy is observed during pregnancy and endurance training. ${ }^{16,17}$ Pathological cardiac hypertrophy is induced by volume and pressure overload or mutations of genes encoding proteins that are involved in force generation, force distribution, and contraction regulation. ${ }^{18-20}$ Two types of hypertrophy are distinguished: Pressure overload is compensated by concentric cardiac hypertrophy because of increased cardiomyocyte diameters, whereas volume overload is compensated by heart chamber enlargement because of cardiomyocyte elongation and increased cardiomyocyte diameter. ${ }^{21,22}$ Pathological hypertrophy is accompanied by adverse cardiac remodeling, which is characterized by fibrosis and reexpression of the fetal gene program comprising natriuretic peptide $\mathrm{A}$, natriuretic peptide $\mathrm{B}$ (NPPB), $\alpha 1$ skeletal muscle actin (ACTA1), and, in mice, myosin heavy chain 7 (Myh7). ${ }^{23,24}$ These alterations are believed to contribute to reduction of cardiac preload and to adaptation of the mechanical and contractile properties of cardiomyocytes to increased mechanical stress. Various signaling pathways are involved in the induction of pathological hypertrophy. Among them, calcineurin-nuclear factor of activated $\mathrm{T}$ cells (Nfat) signaling resembles a key pathway. ${ }^{25}$ The hypertrophic response may become insufficient, eventually leading to end-stage heart failure. ${ }^{21,26}$

The current study was undertaken to analyze the occurrence of cardiomyocyte hypertrophy in AC. Besides cardiac tissue samples obtained from AC patients at end-stage disease, a murine model-desmoglein 2-mutant $\left(D s g 2^{M T}\right)$ mice $^{27}$ - was used to study cardiomyocyte hypertrophy in the distinct disease phases. At birth, $D s g 2^{M T}$ mice show no visible pathological changes; however, the animals develop right ventricular dilation and myocardial lesions from 2 to 3 weeks onwards. ${ }^{27}$ Cardiomyocyte death at the onset of the overt disease phase elicits a transient inflammatory response accompanied and followed by replacement and interstitial fibrosis. By the age of 10 to 12 weeks, disease progression slows down and a chronic progression with dilation of all cardiac chambers and heart failure is observed. ${ }^{27-29}$ In adult animals, a significant prolongation of the QRS complex was noted by electrocardiography. ${ }^{29}$ Furthermore, norepinephrine stimulation was shown to induce ventricular extrasystoles, atrial arrhythmias, and repolarization abnormalities. ${ }^{27}$

Herein, cardiomyocyte diameters were analyzed in left and right ventricles of human and mouse hearts. In addition, cardiac hypertrophy was examined by analyzing hypertrophic marker gene expression. Finally, heart function and the spatial and temporal expression of components of the calcineurin-Nfat signaling pathway were assessed in the AC mouse model.

\section{Materials and Methods}

\section{Human Cardiac Tissue Samples}

Human myocardial tissue samples were obtained from surgical heart transplants at the Heart and Diabetes Center North Rhine-Westphalia. Samples were taken from the explanted hearts of AC patients with end-stage heart failure $(n=5)$. The patients are identical to Patients 1 to 5 described by Kant et al. ${ }^{30}$ The reasons for cardiac transplantation of these patients was right ventricular failure $(n=2)$, predominantly right ventricular failure $(n=2)$, and biventricular failure and cardiac arrhythmias $(n=1)$. Control tissues originate from donor hearts $(n=5)$ that were not suitable for transplantation. After shock freezing, the tissue samples were cryopreserved at $-80^{\circ} \mathrm{C}$ until use. Patients gave informed consent for the use of their explanted hearts (ethical committee votum 21/2013 by the Medical Faculty of the Ruhr-University Bochum, suboffice Bad Oeynhausen).

\section{Animals}

Mice were housed in the animal facility of the University Hospital Rheinisch-Westfälische Technische Hochschule Aachen. Animals received a standard rodent laboratory diet (Ssniff, Soest, Germany) and had free access to food and water. The experiments were conducted in accordance with the guidelines for the care and use of laboratory animals and approved by the Ministry for Climate Protection, Environment, Agriculture, Conservation and Consumer Protection of the State of North Rhine-Westphalia (reference number 8.87-50.10.37.09.114). Homozygous $D s g 2^{M T}$ mice have been described recently. ${ }^{27}$ Cardiac tissue samples were collected from homozygous $D s g 2^{M T}$ and age-matched wildtype $\left(D s g 2^{W T}\right)$ mice of either sex at indicated time points.

For the measurement of cardiomyocyte diameter, hearts were cut transversally, fixed in $4 \%$ neutrally buffered formaldehyde overnight, dehydrated in a graded isopropanol series, and embedded in paraffin. 
To study the mRNA expression of markers indicative of cardiac function and/or hypertrophy, hearts of 4-week-old (juvenile), 12-week-old (adult), and 7- to 8-month-old (aged) mice (each genotype and age $n=5$ to 7 ) were collected for RNA isolation (PeqLab Gold RNA Isolation Kit; PEQLAB Biotechnologie GmbH, Erlangen, Germany). After removal of the atria, the right ventricular free wall was separated and the left ventricle (septum and left ventricular free wall) was cleaned from adherent blood. The cardiac samples were separately homogenized in RNA isolation buffer. RNA isolation was performed according to the manufacturer's protocol.

\section{Assessment of Cardiomyocyte Hypertrophy}

Cryostat sections (10 $\mu \mathrm{m}$ thick) were prepared from frozen human heart samples. Sections were fixed for 10 minutes in $4 \%$ neutrally buffered formaldehyde. After washing in phosphate-buffered saline (PBS), sections were incubated with tetrarhodamine isothiocyanate-labeled wheat germ agglutinin $(100 \mu \mathrm{g} / \mathrm{mL}$ in PBS, 1 hour; catalog number $\mathrm{L}$ 5266; Sigma-Aldrich, Seelze, Germany). Sections were washed twice in PBS, and nuclei were counterstained with DAPI $(2 \mu \mathrm{g} / \mathrm{mL}$ in PBS $)$.

The diameters of murine cardiomyocyte were assessed on paraffin sections (5 $\mu \mathrm{m}$ thick). After paraffin removal with xylene, sections were rehydrated in a graded alcohol series and transferred to PBS. Antigen retrieval was achieved by incubating sections in $10 \mathrm{mmol} / \mathrm{L}$ citrate buffer $(\mathrm{pH} 6)$ for 30 minutes at $94^{\circ} \mathrm{C}$. Thereafter, sections were incubated with tetrarhodamine isothiocyanate-labeled wheat germ agglutinin and counterstained with DAPI.

Cardiomyocyte diameters were measured in images taken with $20 \times$ and $40 \times$ objectives of the ApoTome.2 (Zeiss, Oberkochen, Germany) using Axiovision software version 4.83 (Zeiss). Three to six images were recorded from each right and left ventricle of all studied animals. In mutants and wild-type controls, images were taken from similar myocardial regions. Subsequent analyses were performed blinded to the genotype (Mus.G.). The cell diameter was determined in cardiomyocyte cross sections containing a visible nucleus in the cell center. In each instance, the shortest diameter was determined along a line through the nucleus. For highest accuracy, the inner diameter of the wheat germ agglutinin-labeled cardiomyocytes was measured. The analyses were verified by a second blinded observer (C.A.K.). The interobserver variability was $5.71 \%$.

\section{IgG Immunostaining to Detect Necrotic and Damaged Cardiomyocytes}

Paraffin sections (5 $\mu \mathrm{m}$ thick) of $D s g 2^{M T}$ and wild-type hearts were used to assess cardiac IgG distribution. ${ }^{31}$ Sections were deparaffinized in xylene and rehydrated in a graded alcohol series. The inactivation of the endogenous peroxidase was included in the rehydration process by adding $3 \% \mathrm{H}_{2} \mathrm{O}_{2}$ to $70 \%$ ethanol and incubation for
10 minutes in the dark. After a rinse of 5 minutes with Tris wash buffer $(0.05 \mathrm{~mol} / \mathrm{L}$ Tris $/ \mathrm{HCl}, \mathrm{pH} 7.5,0.3 \mathrm{~mol} / \mathrm{L} \mathrm{NaCl}$, and $0.045 \%$ Tween 20), sections were transferred for 30 minutes to $10 \mathrm{mmol} / \mathrm{L}$ citrate buffer ( $\mathrm{pH}$ 6) heated to $94^{\circ} \mathrm{C}$ in a water bath. After cooling down to room temperature (20 minutes), murine IgG was detected with the Zytochem Plus HRP-Polymer mouse/rabbit system (catalog number POLHRP-100; Zytomed Systems, Berlin, Germany). At first, the blocking solution was applied for 5 minutes, followed by a 5-minute rinse in Tris wash buffer. Then, sections were incubated with reagent 2 for 30 minutes, washed with Tris wash buffer ( 2 washes for 5 minutes each), followed by treatment with the horseradish peroxidase (HRP)-polymer solution for 30 minutes. After two washes of 5 minutes each, sections were rinsed with distilled water. The immunoreaction was detected with diaminobenzidine and hydrogen peroxide (diaminobenzidine substrate kit; catalog number TA-060-QHDX; Zytomed Systems). After counterstaining with hematoxylin, sections were mounted with glycerol gelatine (Merck, Darmstadt, Germany).

$D s g 2^{M T}$ and wild-type animals, aged 2, 4, 5 to 6, 11 to 13 , and 47 to 54 weeks, were assessed ( $n=3$ to 6 animals per age group and genotype).

\section{mRNA Expression Analysis}

Total cardiac mouse RNA $(1 \mu \mathrm{g})$ was reverse transcribed using the Transcriptor First Strand cDNA Synthesis Kit and oligo-(dT) 18 primer (Roche, Mannheim, Germany). PCR was performed on cDNA using the LightCycler 96 system and the Fast Start Essential DNA Probes Master Kit (Roche). The PCR volume was $10 \mu \mathrm{L}$ and contained the equivalent of $30 \mathrm{ng}$ total RNA. Primer and Universal Probe Library (UPL) probes (Roche) were used at a concentration of 0.5 and $0.1 \mu \mathrm{mol} / \mathrm{L}$, respectively. The PCR program consisted of a preincubation step $\left(95^{\circ} \mathrm{C}, 10\right.$ minutes) followed by 45 two-step amplification cycles (denaturation: 10 seconds, $95^{\circ} \mathrm{C}$; annealing/elongation: 30 seconds, $60^{\circ} \mathrm{C}$ ) with measurement of PCR product formation at the end of each cycle. Hydroxymethylbilane synthase served as the housekeeping gene. Results are given as means \pm SD.

To assess the mRNA expression in murine right and left ventricular samples, the following primer pairs and UPL probes were used for quantitative RT-PCR: Nppb: UPL-probe 71, 5'-GTCAGTCGTTTGGGCTGTAAC- $3^{\prime}$ (forward) and 5'-AGACCCAGGCAGAGTCAGAA-3' (reverse); Myh7 (cardiac muscle, $\beta$ ): UPL-probe 85, 5'-TGAAGCTGACGCAGGAGAG-3' (forward) and 5'-TGAGTGCATTTAACTCAAAGTCC-3' (reverse); Acta1 (skeletal muscle actin): UPL-probe $9,5^{\prime}$-TCCTCCCTGGAGAAGAGCTA-3 ${ }^{\prime}$ (forward) and 5'-ATCCCCGCAGACTCCATAC-3' (reverse); phospholamban: UPL-probe 27, $5^{\prime}$ TGAGCTTTCCTGCGTAACAG- $3^{\prime}$ (forward) and $5^{\prime}$ TGGTCAAGAGAAAGATAAAAAGTTGA-3' (reverse); sarcoplasmic/endoplasmic reticulum calcium ATPase 2: UPL-probe 15, 5'-TGTTGAGTTCCTTCAGTCCTTTG 3' 
(forward) and 5'-GGCAATCCCGATTTCAGAT-3' (reverse); regulator of calcineurin 1 (Rcan1): UPL-probe 77, 5' -AAAGCCACCAAGTGTCCAGT-3' (forward) and 5'-GACAATTCCACACGGTTCG-3' (reverse); hydroxymethylbilane synthase: UPL-probe 42, 5'-AAGTTCCCCCACCTGGAA-3' (forward) and 5'-GACGATGGCACTGAATTCCT-3' (reverse).

mRNA expression was examined in right and left ventricular samples of five AC patients and five nonfailing donors. Total RNA was isolated with the RNeasy Mini Kit (Qiagen, Hilden, Germany), according to the manufacturer's recommendation. Total RNA (250 ng) was reverse transcribed (SuperScript Reverse Transcriptase, random primers; Invitrogen, Life Technologies, Dreieich, Germany). For realtime PCR, $2 \mu \mathrm{L}$ of cDNA was used in a total volume of 20 $\mu \mathrm{L}$. Primers and corresponding FAM- and TAMRA-labeled probes were used at concentrations of 0.30 and $0.15 \mu \mathrm{mol} / \mathrm{L}$, respectively. The PCR program consisted of a preincubation step $\left(95^{\circ} \mathrm{C}, 10\right.$ minutes) followed by 40 two-step amplification cycles (denaturation: 15 seconds, $95^{\circ} \mathrm{C}$; annealing/elongation: 60 seconds, $60^{\circ} \mathrm{C}$ ) with measurement of the fluorescence signal at the end of each cycle. For the determination of the relative quantity, glyceraldehyde-3-phosphate dehydrogenase was used as reference.

The following primer pairs and probes were used to analyze the mRNA expression in human right and left ventricular samples: glyceraldehyde-3-phosphate dehydrogenase, $5^{\prime}$ CTGGGCTACACTGAGCACCA-3' (forward), 5'-CAGCGTCAAAGGTGGAGGAG-3' (reverse), $5^{\prime}$-TGGTCTCCTCTGACTTCAACAGCGACAC-3' (probe); NPPB, 5'-AGGAGCAGCGCAACCATTT-3' (forward), 5'-TCCAGGGATGTCTGCTCCA-3' (reverse), 5'-CAGGGCAAACTGTCGGAGCTGCA-3' (probe); sarcoplasmic reticulum $\mathrm{Ca}^{(2+)-}$ ATPase 2 (ATP2A2), 5'-GTCCTTGCTGAGGATGCCC-3' (forward), 5'-TGACATGGACAGGCAGATGG-3' (reverse), 5'-CCTGGGAGAACATCTGGCTCGTGG-3' (probe); ACTA1, 5'-GAGCGTGGCTACTCCTTCGT-3' (forward), 5'-GTAGCACAGCTTCTCCTTGATGTC-3' (reverse), 5'-ACCACAGCTGAGCGCGAGATCGT-3' (probe); and MYH7, 5'AAGGTCAAGGCCTACAAGCG-3' (forward), $5^{\prime}$-CTTGCGGAACTTGGACAGGT-3' (reverse), 5'-AGGAGGCGGAGGAGCAAGCCAAC-3' (probe).

\section{In Situ Hybridization}

Paraffin sections ( $5 \mu \mathrm{m}$ thick) were prepared under RNase free conditions. In situ hybridization was performed with the help of the View RNA ISH Tissue Assay Kit and the View RNA Chromogenic Signal Amplification Kit (both from Affymetrix, Santa Clara, CA; catalog numbers QVT0050 and QVT0200, respectively) using type 1 view RNA probes against Actc1 (Affymetrix; catalog number VB1-13263), and Nfatc1, Nfatc2, Nfatc3, and Nfatc4 (https://www.ncbi.nlm.nih. gov/gene; accession numbers NM_016791.4, NM_010899.3, NM_010901, and NM_023699.3, respectively).

The procedure was performed according to the protocol provided by the manufacturer using a programable temperature-controlled slide processing instrument (ThermoBrite; Abbott Laboratories, Abbott Park, IL). The heat and protease pretreatment protocols were optimized in a pilot experiment. As a result, sections were incubated in pretreatment solution for 20 minutes at $95^{\circ} \mathrm{C}$ to $98^{\circ} \mathrm{C}$ and digested in protease solution for 20 minutes at $40^{\circ} \mathrm{C}$. Specifically, hybridized probes were detected with Fast Red. The reaction was visually controlled using an ApoTome 2 microscope setup controlled by AxioVision imaging software version 4.8 (Zeiss, Jena, Germany). To better visualize the fluorescence signals, the contrast was confined between the maximum fluorescence intensity of erythrocytes and the maximum fluorescence intensity of the entire image. The resulting high-contrast fluorescence image was then overlaid with the corresponding bright field image (Supplemental Figure S1, A and B). Localization of Actc1 mRNA was performed to control for mRNA integrity and to monitor the effectiveness of the pretreatment protocol (Supplemental Figure S1C). To test for unspecific binding, hybridization probes were omitted (Supplemental Figure S1D).

\section{Immunoblots}

Right and left ventricles of dissected hearts were separately homogenized in protein extraction buffer $[10 \mathrm{mmol} / \mathrm{L}$ Tris, $2 \mathrm{mmol} / \mathrm{L} \mathrm{MgCl}_{2}, 10 \mathrm{mmol} / \mathrm{L} \mathrm{KCl}, 2 \%$ (w/v) SDS, $\mathrm{pH}$ 8.0] supplemented with one tablet complete mini protease inhibitor and one tablet PhosStop phosphatase inhibitor (both from Roche) per $10 \mathrm{~mL}$ buffer using a glass-Teflon homogenizer. After centrifugation (20 minutes, $17,000 \times g, 4^{\circ} \mathrm{C}$ ), the protein content of the supernatants was assessed with the DC Protein Assay Kit (BioRad, Munich, Germany). Right or left ventricular proteins (40 $\mu \mathrm{g})$ were separated either in an $8 \%$ SDS-polyacrylamide gel (Myh7 detection) or a 10\% SDS-polyacrylamide gel (Nppb detection) and blotted onto polyvinylidene difluoride membranes by tank blotting. After transfer, polyvinylidene difluoride membranes were blocked with 5\% milk powder in tris-buffered saline with Tween 20 (TBS-T) buffer $[50 \mathrm{mmol} / \mathrm{L}$ Tris/ $\mathrm{HCl}, 150 \mathrm{mmol} / \mathrm{L} \mathrm{NaCl}, 0.1 \%$ (v/v) Tween 20, pH 7.6] for 2 hours at room temperature and then incubated overnight at $4{ }^{\circ} \mathrm{C}$ with the specific antibodies diluted in TBS-T buffer containing $1 \%$ milk powder. The anti-Nppb antibody (goat polyclonal; V17; sc-67455; Santa Cruz Biotechnology, Dallas, TX) and the anti-Myh7 antibody (mouse monoclonal; A4.840; sc-53089 from Santa Cruz) were diluted 1:200, whereas the anti- $\beta$-actin antibody (rabbit polyclonal, Sigma, A 2066) was diluted 1:2000. On the following morning, the blots were washed three times in TBS-T buffer and incubated for 1 hour with the respective secondary antibody (rabbit anti-goat-HRP conjugate, goat anti-mouse-HRP conjugate, goat anti-rabbit-HRP conjugate; all from Dako, Hamburg, Germany), each diluted 1:5000 in TBS-T buffer with $1 \%$ milk powder. After three washes with TBS-T, the immunoblots 
were reacted with a chemiluminescence substrate (ECL Prime Western Blotting Detection Reagent; GE Health Care Life Sciences, Freiburg, Germany).

\section{Echocardiography}

Two-dimensional (B-mode) and M-mode echocardiographic measurements (Vevo 770; Visual Sonics, Toronto, ON, Canada) were performed. Mice were anesthetized by mask with $1.5 \%$ isoflurane and placed in supine position on a warming pad. The ejection fraction, cardiac output, left ventricular end-diastolic diameter, left ventricular end-systolic diameter, heart rate, and heart weight were recorded and analyzed, as previously described. ${ }^{32}$

\section{Statistical Analysis}

To compare two groups, the Mann Whitney $U$-test (two tailed) was applied. In case of echocardiography, statistical analyses were performed by two-way analysis of variance with respect to age and genotype and post hoc Bonferroni's multiple comparison tests with selected groups: i) $D s g 2^{W T}$ 7 weeks versus $D s g 2^{W T} 13$ weeks, ii) $D s g 2^{M T} 6$ weeks versus $D s g 2^{M T} 13$ weeks, iii) $D s g 2^{W T} 7$ weeks versus
$D s g 2^{M T} 6$ weeks, and iv) $D s g 2^{W T} 13$ weeks versus $D s g 2^{M T}$ 13 weeks. $P<0.05$ was considered as statistically significant. Statistics were performed using GraphPad Prism version 5.01 or version 7 (GraphPad Software, Inc., La Jolla, CA).

\section{Results}

\section{Cardiomyocyte Diameter Is Increased in the Right Ventricle of End-Stage AC Patients}

The diameter of right and left ventricular cardiomyocytes was compared between end-stage AC hearts and nonfailing control hearts (Figure 1). The diameter of left ventricular cardiomyocytes did not differ between AC hearts and nonfailing control hearts (Figure 1A). In contrast, the diameter of right ventricular cardiomyocytes was significantly increased in AC hearts compared to control hearts $(30.11 \pm 1.93 \mu \mathrm{m}$ versus $18.69 \pm 2.67 \mu \mathrm{m} ; P=0.0317)$ (Figure 1B). Comparison of cardiomyocyte diameter in the right and left ventricle of $\mathrm{AC}$ hearts revealed a significantly higher diameter in the right ventricle $(30.11 \pm 1.93 \mu \mathrm{m}$ versus $22.15 \pm 1.91 \mu \mathrm{m}$, respectively; $P=0.0317$ ), whereas there was no significant difference between right
A

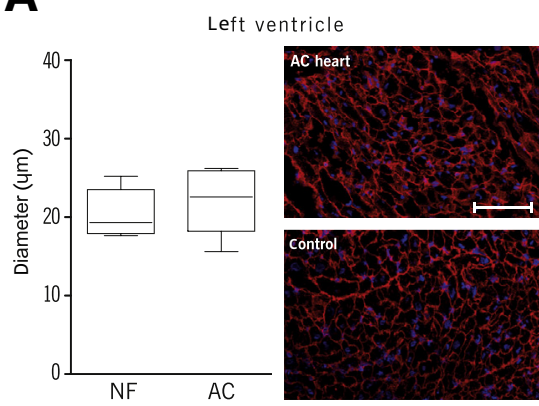

D

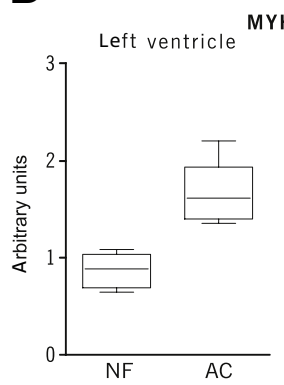

B

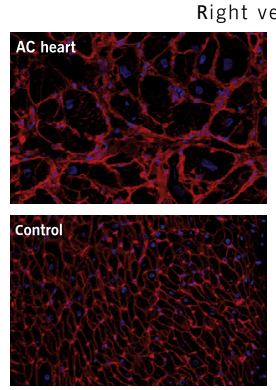

$\mathbf{E}$

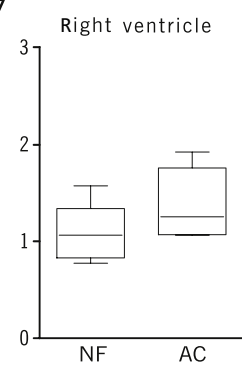

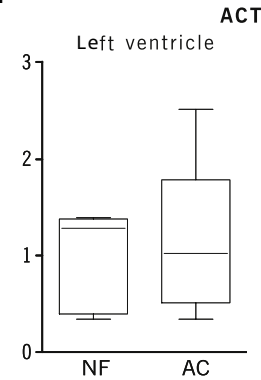

C

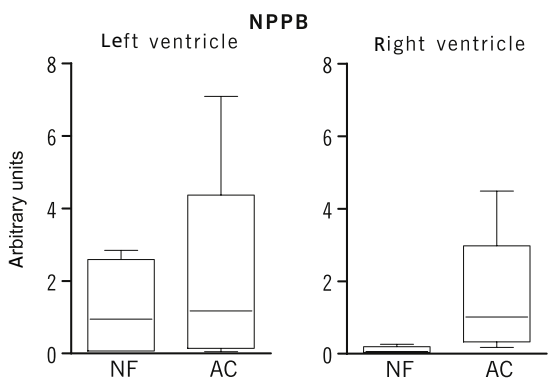

$\mathbf{F}$

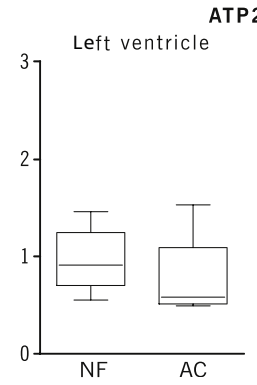

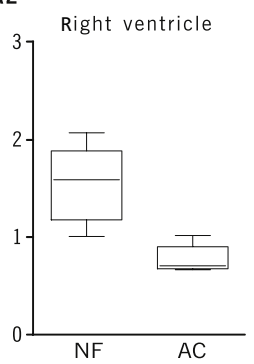

Figure 1 Arrhythmogenic cardiomyopathy $(\mathrm{AC})$ patients with end-stage heart failure display cardiomyocytes with increased diameter in the right ventricle and altered mRNA expression of NPPB, MYH7, and ATP2A2. A and B: Summary measurements of cardiomyocyte diameter from AC patients and nonfailing control donors (NF) and present examples of fluorescence images of heart sections that were used for these measurements. Cryostat sections were stained with tetrarhodamine isothiocyanate-labeled wheat germ agglutinin (red) to delineate the plasma membrane and with DAPI (blue) to visualize nuclei in hearts from AC patients and NF controls. Left ventricular cardiomyocyte $(A)$ diameters do not differ between $A C$ and NF heart but the diameter of right ventricular cardiomyocytes $(\mathbf{B})$ is significantly increased in AC hearts compared to NF hearts $(P=0.0317)$. C $-\mathrm{F}$ : Results of quantitative RT-PCR. Note that in the right ventricle of AC patients, NPPB mRNA (C) is significantly up-regulated and ATP2A2 mRNA is significantly down-regulated (both $P=0.0159 ; \mathbf{F})$. Furthermore, MYH7 mRNA is selectively increased in the left ventricle of $A C$ patients $(P=0.0079 ; \mathbf{D})$, whereas no changes are detected for ACTA1 (E) in either ventricle in comparison to the controls. Data are presented as Tukey's whisker plots. Scale bar $=100 \mu \mathrm{m}$ (A and B). 
and left ventricular cardiomyocyte diameters in the nonfailing hearts $(18.69 \pm 2.67 \mu \mathrm{m}$ versus $20.42 \pm 1.4 \mu \mathrm{m}$, respectively; $P=0.6905)$.

Differential Changes in mRNA Expression in the Right and Left Ventricle Indicate Specialized Modes of

\section{Stress Response}

Because pathological hypertrophy is accompanied by the reactivation of the fetal gene program and disturbance of calcium handling, ${ }^{24,33} \mathrm{mRNA}$ expression of brain natriuretic peptide (NPPB), skeletal muscle actin (ACTA1), $\beta$ myosin heavy chain (MYH7), and the ATP2A2 was studied by quantitative RT-PCR (Figure 1, C-F). NPPB mRNA was selectively up-regulated in the right ventricle of $\mathrm{AC}$ hearts compared to the nonfailing hearts $(P=0.0159)$. MYH7 mRNA expression was selectively increased in the left ventricle of AC hearts compared to the nonfailing hearts $(P=0.0079)$ (Figure 1D). ATP2A2 mRNA expression was significantly reduced in the right ventricle of AC patients $(P=0.0159)$ compared to nonfailing heart samples (Figure 1F). Taken together, these changes reflect chamberspecific expression alterations in the AC hearts.
Cardiac Dilation, Elevated Heart Weight, and Increased Cardiomyocyte Diameter Are Observed at Advanced Disease Stages in a Murine Model of AC

As an end-stage correlate, we assessed cardiomyocyte hypertrophy in 10- to 14-month-old $D s g 2^{M T}$ mice, which correspond to 38- to 48-year-old humans. ${ }^{34}$ Of 29 studied $D s g 2^{M T}$ mice, 28 (96.5\%) displayed morphological cardiac alterations in comparison to age-matched wild-type control mice (Figure 2, A-D). Figure 2B depicts the rarely occurring mild phenotype with slight biventricular dilation. In most instances, mutant mice presented extreme dilation of the right ventricle and extensive thinning of the right ventricular wall with aneurysm formation (Figure 2, C and D). The left ventricle was also considerably dilated in most cases and showed fibrosis (Figure 2C). Furthermore, the atria were often grossly enlarged (Figure 2, C and D) and displayed fibrotic wall changes.

To examine cardiomyocyte hypertrophy, tetrarhodamine isothiocyanate-wheat germ agglutinin staining was performed in right and left ventricular walls of $D s g 2^{M T}$ mice and $D s g 2^{W T}$ controls (Figure 2, E-J). The quantitative assessment revealed a significant increase of
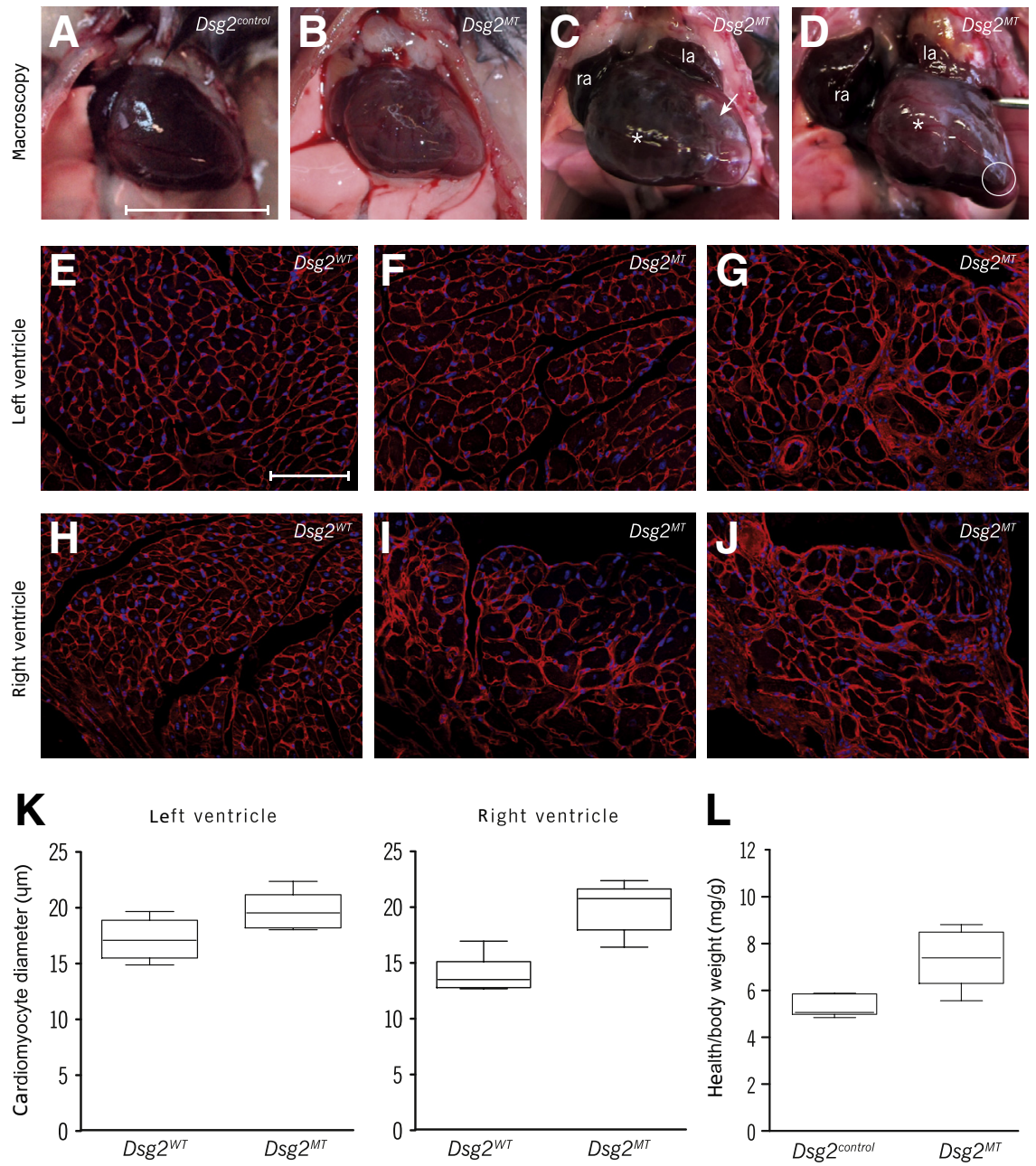

Figure 2 One-year-old $D s g 2^{M T}$ mice present with cardiac dilation and significantly increased diameter of right and left ventricular cardiomyocytes. A-D: Cardiac morphology at autopsy in 1-year-old control mice (Dsg2 $2^{\text {control; }}$; A) and $D s g 2^{M T}$ hearts (B-D), which present with various pathologies, including pronounced dilation of the right and left ventricle (asterisks in C and D), aneurysms (circle in D), overt ventricular fibrosis (arrow in C), and dilation of the right and left atrium ( $r$ and la, respectively; $\mathbf{C}$ and $\mathbf{D}$ ). E-J: Representative tetrarhodamine isothiocyanate-labeled wheat germ agglutinin (red)- and DAPI (blue)-stained paraffin sections of the left ( $\mathbf{E}$ $-\mathbf{G})$ and right ventricle $(\mathbf{H}-\mathbf{J})$ of 9 - to 12-monthold $D s g 2^{W T}$ (E and $\left.\mathbf{H}\right)$ and $D s g 2^{M T}(\mathbf{F}, \mathbf{G}, \mathbf{I}$, and $\mathbf{J})$ mice. K: The whisker boxplots depict results of measurements of cardiomyocyte diameter in the left and right ventricle of 1-year-old wild-type and $D s g 2^{M T}$ mice. The cardiomyocyte diameter of right ventricular cardiomyocytes is significantly higher in $D s g 2^{M T}$ mice than in age-matched wild-type mice $(P<0.0087)$. L: Comparison of the heart/ body weight ratios in morphologically inconspicuous heterozygous Dsg2-mutant mice (Dsg2 ${ }^{\text {control }}$ ) and $D s g 2^{M T}$ mice. A significant increase of the heart/body weight ratio is detected in Dsg2 $2^{M T}$ mice compared to the controls $(P=0.0173)$. Data are presented as Tukey's whisker plots. $n=5$ (K and $\mathbf{L}, D s g 2^{M T}$ mice); $n=6$ ( $\mathbf{K}$, wild-type mice) $n=7$ (L, controls). Scale bars: $1 \mathrm{~cm}$ (A-D); $100 \mu \mathrm{m}$ (E-J). 
cardiomyocyte diameter in the right ventricle of old $D s g 2^{M T}$ mice $(P=0.0087)$. Left ventricular cardiomyocytes also presented with considerably elevated diameters $(P=0.0823)$ (Figure $2 \mathrm{~K})$. The heart/body weight ratio was significantly increased in these $D s g 2^{M T}$ mice $(P=0.0101)$ (Figure $2 \mathrm{~L})$ compared to the agematched controls.

\section{Damaged or Necrotic Cardiomyocytes Are Detected Before Cardiomyocyte Hypertrophy in Dsg2 ${ }^{M T}$ Mice}

Because the monitoring of cardiomyocyte diameters during disease progression is not feasible in AC patients, we studied the hypertrophic response in the murine $D s g 2^{M T}$ AC model. ${ }^{27-29}$

The acute/overt AC phase is marked by the occurrence of myocardial lesions and dilation of heart chambers in these animals at an age of 2 to 4 weeks. ${ }^{27,28}$ Because our observations suggested that the $D s g 2$ mutation weakens cardiomyocyte adhesion and stability of the cytoskeleton, we hypothesized that mechanical stress may induce sarcolemmal damage in the mutant heart early on, leading to cardiomyocyte necrosis, as has been described for muscular dystrophy. ${ }^{31}$ To test this hypothesis, we localized IgG in mutant (Figure 3, A-E) and wild-type hearts (Figure 3, $\mathrm{F}-\mathrm{H})$ by immunohistochemistry. Figure $3 \mathrm{~A}$ shows the staining of a 2-week-old $D s g 2^{M T}$ mouse heart with intracellular IgG accumulation in necrotic regions (Supplemental Figures S2 and S3). Furthermore, cardiomyocytes with normal morphology and intracellular IgG were detected in $D s g 2^{M T}$ mice at 2 to 4 weeks, indicating membrane leakiness and cardiomyocytes prone to necrosis (Figure 3B). Later in the disease course, IgG-positive cardiomyocytes were only occasionally detected in $D s g 2^{M T}$ hearts (Figure 3, $\mathrm{C}$ and $\mathrm{D})$. Taken together, we conclude that AC pathology starts approximately 2 to 4 weeks after birth, with increased cardiomyocyte fragility.

To find out whether hypertrophy occurs already at this early disease stage, cardiomyocyte diameters were examined in 2- and 4-week-old Dsg2 ${ }^{M T}$ mice (Figure 4). No increase was noted in comparison to the wild-type (Figure 4, A and B). However, cardiomyocyte diameter significantly increased in 6-week-old $D s g 2^{M T}$ mice (Figure 4C), and this increase was maintained up to an age of 11 to 13 weeks (Figure 4, D and E). At this age, the heart/body weight ratio was also significantly elevated in $D s g 2^{M T}$ compared to control mice (Figure 4F).

To find out whether cardiomyocyte hypertrophy compensates functionally for cardiomyocyte loss, seven $D s g 2^{M T}$ mice were examined by echocardiography at the age of 6 and 13 weeks and compared to six wild-type mice (Table 1). Functional parameters of both ventricles did not differ significantly from those in the wild-type controls between 6 and 13 weeks in six of the $D s g 2^{M T}$ mice. One $D s g 2^{M T}$ mouse, however, presented with a significant reduction of the right ventricular ejection fraction in this period (44\% at 6 weeks and only $17 \%$ at 13 weeks). At the same time, left ventricular weight was significantly increased in the 13-week-old $D s g 2^{M T}$ mice in comparison to 6-week-old $D s g 2^{M T}$ and wild-type mice (Table 1), indicating macroscopic manifestation of cardiomyocyte hypertrophy. Yet, chamber dimensions and function of the right and left

\section{Detection of intracellular IgG}
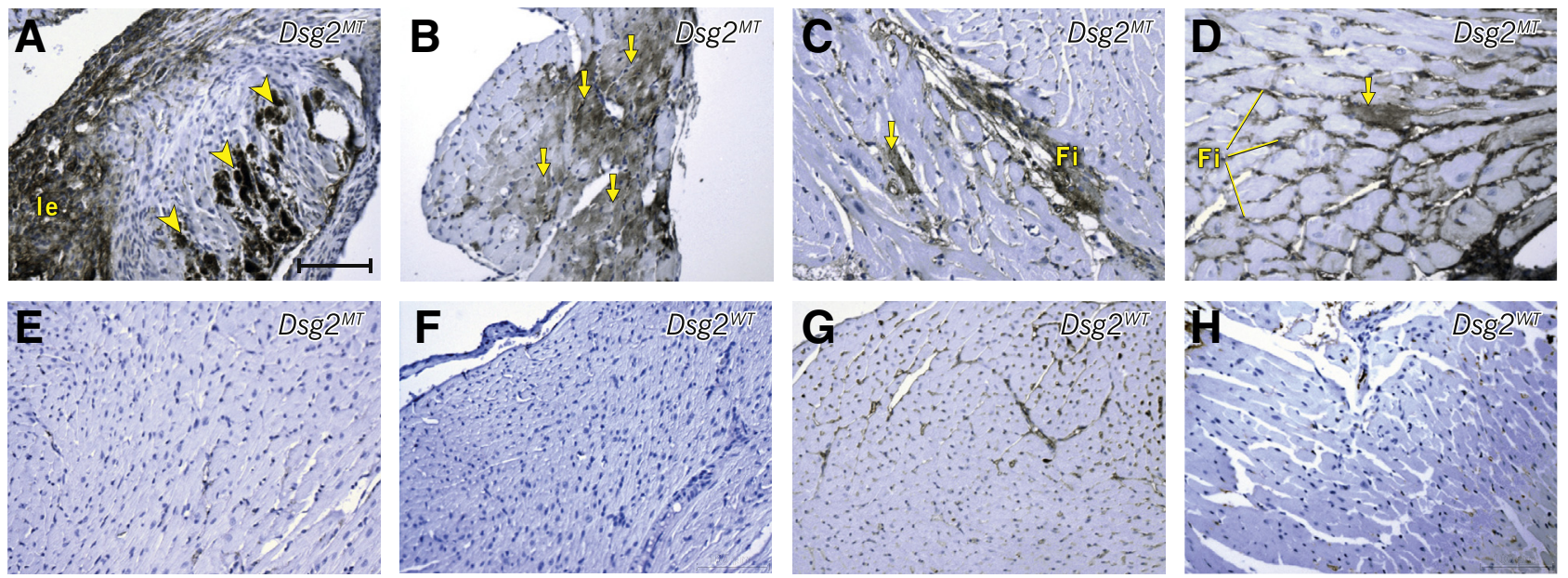

Figure 3 Intracellular serum IgG indicates loss of cardiomyocyte membrane integrity and beginning of cardiomyocyte necrosis. A-D: Sections of $D s g 2^{M T}$ mice at acute disease onset ( 2 to 4 weeks; $\mathbf{A}$ and $\mathbf{B}$ ), the end of the acute phase (11 to 13 weeks; $\mathbf{C}$ ), and during the chronic phase in progression to heart failure (51 weeks; D). A and B: At the beginning of the overt phase, IgG staining is frequently detected in myocardial lesions (le) with necrotic cardiomyocytes (arrowheads). In addition, cardiomyocytes with normal morphology are IgG positive, indicating membrane damage and/or leakiness (arrows). C and D: During chronic progression to heart failure, IgG staining is detected in fibrotic areas (Fi) and single cardiomyocytes (arrows). E: An unaffected myocardial area of a 4-week-old $D s g 2^{M T}$ mouse is shown. F-H: Wild-type hearts of the corresponding ages are depicted in $\mathbf{F}$ (5 weeks), G (13 weeks), and $\mathbf{H}$ (51 week), indicating that IgG staining is physiologically confined to the blood vessels. In contrast, IgG-positive cardiomyocytes are absent or extremely rare in wild-type mice. Scale bar $=100 \mu \mathrm{m}(\mathbf{A}-\mathbf{H})$. 

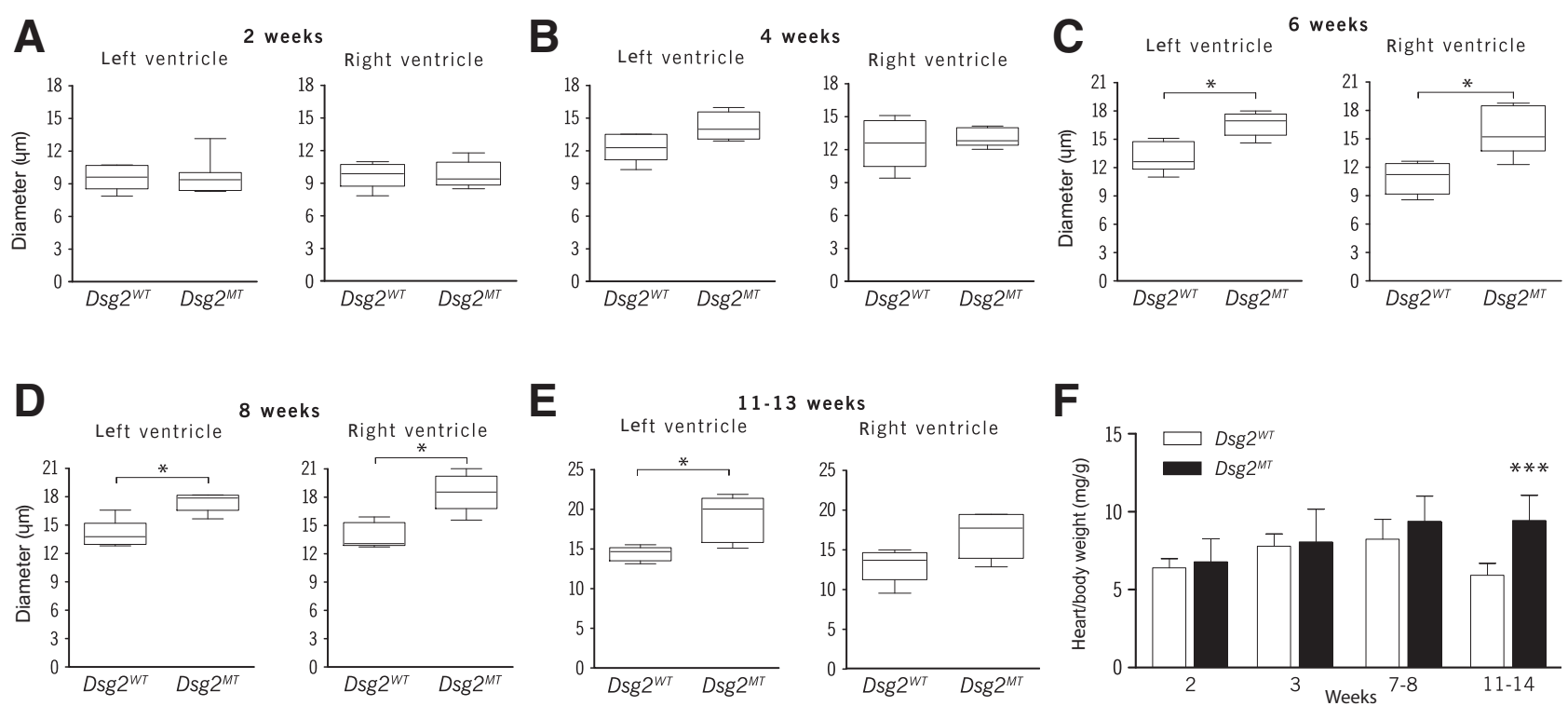

Figure 4 The development of cardiomyocyte hypertrophy starts after morphological disease onset. A-E: Comparisons of cardiomyocyte diameter in the left and right ventricles of $D s g 2^{M T}$ and $D s g 2^{W T}$ mice aged 2 to 12 weeks. Although the mean values of right ventricular cardiomyocytes of $D s g 2^{M T}$ and $D s g 2^{W T}$ mice differ by $3.8 \mu \mathrm{m}$ at 12 weeks, there is only a trend toward statistical significance $(P=0.0952)$. F: Heart/body weight ratios in $D s g 2^{W T}$ and $D s g 2^{M T}$ mice between the age of 2 and 11 to 14 weeks. Significant differences are observed at an age of 11 to 14 weeks. Data are presented as Tukey's whisker plots (A-E) or as means $\pm \operatorname{SEM}(\mathbf{F}) . n=5$ to 7 per age group and genotype $\left(\mathbf{A}-\mathbf{E}, D s g 2^{M T}\right.$ and $D s g 2^{W T}$ mice $) ; n=9\left(\mathbf{F}, D s g 2^{W T}\right) ; n=7\left(\mathbf{F}, D s g 2^{M T}\right)$. ${ }^{*} P<0.05$, $* * * P<0.001$

ventricle did not differ significantly between $D s g 2^{M T}$ and $D s g 2^{W T}$ mice, although a trend toward chamber dilation and reduction of ventricular ejection fraction was detectable in $D s g 2^{M T}$ mice. Notably, the pulmonalis peak gradient was significantly reduced in 13 -week-old $D s g 2^{M T}$ mice in comparison to $D s g 2^{M T}$ mice, indicating an impaired right ventricular function.

\section{Markers of Pathological Hypertrophy Increase during the Acute and Chronic Disease Phases}

Right and left ventricular disease status was further monitored by examining the mRNA expression of markers for cardiac function and pathological hypertrophy (Figure 5, $\mathrm{A}-\mathrm{F}$, and Table 2). Expression was assessed after disease

Table 1 Heart Function Studied by Echocardiography in Sedated $D s g 2^{W T}$ and $D s g 2^{M T}$ Mice at 6 and 13 Weeks

\begin{tabular}{|c|c|c|c|c|}
\hline \multirow[b]{2}{*}{ Variable } & \multicolumn{2}{|l|}{$D s g 2^{W T}$} & \multicolumn{2}{|l|}{$D s g 2^{M T}$} \\
\hline & 7 weeks $(n=6)$ & 13 weeks $(n=6)$ & 6 weeks $(n=7)$ & 13 weeks $(n=7)$ \\
\hline \multicolumn{5}{|l|}{ Left ventricle } \\
\hline Left ventricular weight, mg & $72.72 \pm 4.92$ & $72.18 \pm 7.29^{* \dagger}$ & $69.01 \pm 6.85$ & $99.34 \pm 8.91^{* \ddagger}$ \\
\hline Hypertrophic index & $3.2 \pm 0.22$ & $2.68 \pm 0.24$ & $2.92 \pm 0.31$ & $3.57 \pm 0.34$ \\
\hline LVIDs, mm & $2.80 \pm 0.10$ & $2.58 \pm 0.21$ & $3.31 \pm 0.17$ & $3.26 \pm 0.19$ \\
\hline LVIDd, mm & $3.68 \pm 0.07$ & $3.56 \pm 0.14$ & $3.98 \pm 0.17$ & $3.86 \pm 0.13$ \\
\hline Ejection fraction, \% & $48.34 \pm 3.13$ & $54.24 \pm 4.63$ & $37.44 \pm 5.28$ & $38.06 \pm 5.37$ \\
\hline Fractional shortening, \% & $24.03 \pm 1.82$ & $28.6 \pm 3.17$ & $19.96 \pm 3.25$ & $21.64 \pm 3.55$ \\
\hline Aorta peak gradient & $1.70 \pm 0.24$ & $2.46 \pm 0.22^{* \star \S}$ & $1.5 \pm 0.17$ & $2.3 \pm 0.5^{\star * \star \ddagger}$ \\
\hline \multicolumn{5}{|l|}{ Right ventricle } \\
\hline RVIDs, mm & $3.13 \pm 0.18$ & $3.09 \pm 0.31$ & $3.27 \pm 0.28$ & $3.44 \pm 0.25 \pi$ \\
\hline RVIDd, mm & $3.67 \pm 0.19$ & $3.70 \pm 0.27$ & $3.71 \pm 0.26$ & $4.01 \pm 0.27^{\pi}$ \\
\hline Ejection fraction, \% & $31.4 \pm 5.35$ & $35.98 \pm 4.30$ & $31.92 \pm 2.91$ & $27.70 \pm 3.12$ \\
\hline Fractional shortening. \% & $14.63 \pm 2.91$ & $17.2 \pm 2.29$ & $23.16 \pm 1.95$ & $21.38 \pm 4.01$ \\
\hline Pulmonalis peak gradient & $1.32 \pm 0.22$ & $1.56 \pm 0.23^{* \dagger}$ & $1.33 \pm 0.15$ & $0.89 \pm 0.09 \pi$ \\
\hline
\end{tabular}

The parameters are given as means \pm SEM. Statistical analyses were performed by two-way analysis of variance and post hoc Bonferroni's multiple comparison tests with selected groups.

$* P<0.05,{ }^{*} P<<0.01$, and $* * * P<0.001$

${ }^{\dagger} D s g 2^{W T} 13$ weeks versus $D s g 2^{M T} 13$ weeks.

${ }^{\ddagger} D s g 2^{M T} 6$ weeks versus $D s g 2^{M T} 13$ weeks.

${ }^{\S} \mathrm{Dsg2} 2^{W T} 7$ weeks versus 13 weeks.

$\Phi_{n}=6$ because of missing data at one time point caused by technical difficulties.

$D s g 2^{M T}$, desmoglein 2 mutant; $D s g 2^{W T}$, desmoglein 2 wild type; LVIDd, left ventricle inner diameter in diastole; LVIDs, left ventricle inner diameter in systole; RVIDd, right ventricle inner diameter in diastole; RVIDs, right ventricle inner diameter in systole. 


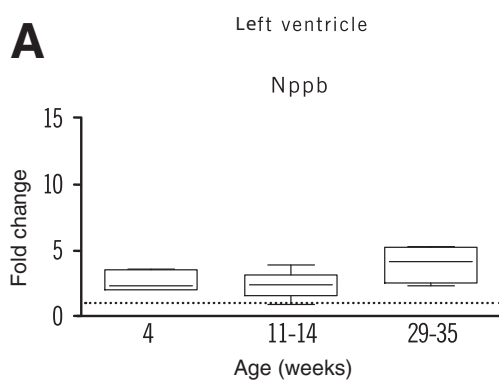

C

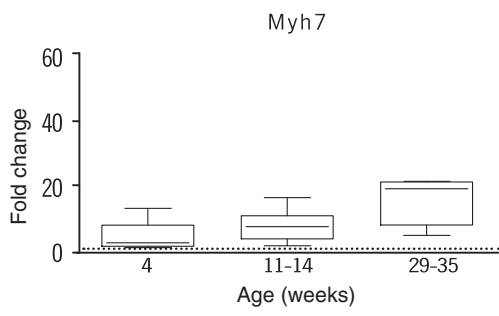

E

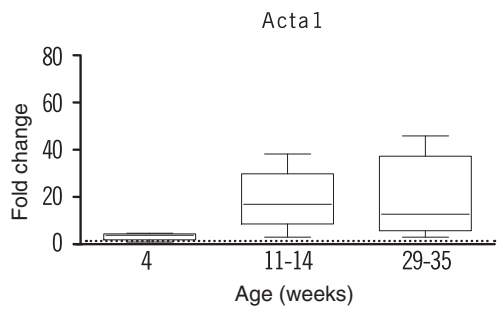

H

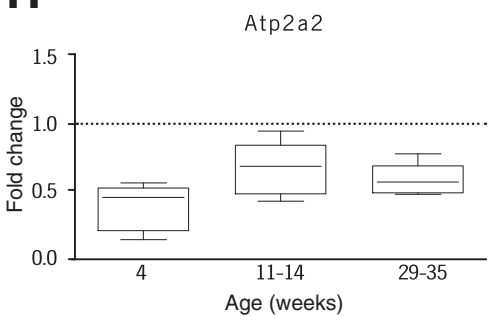

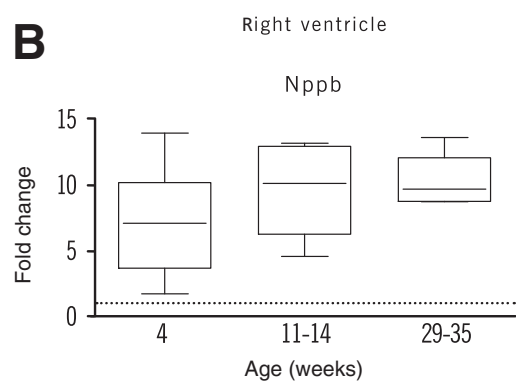

D

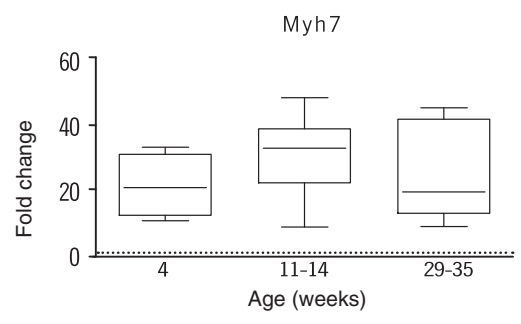

$\mathbf{F}$

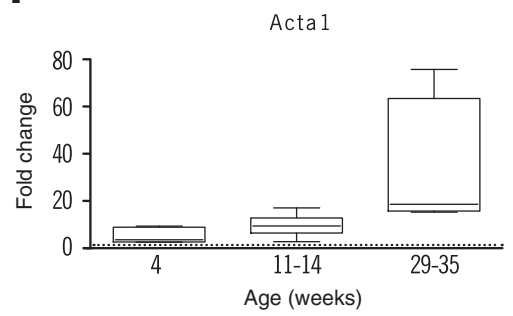

I

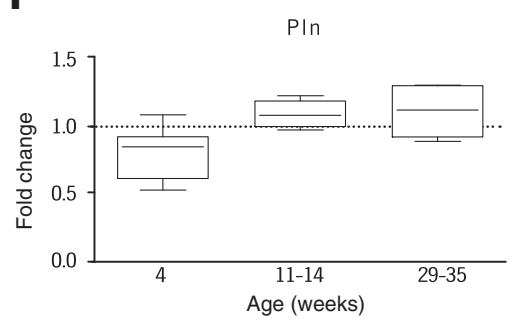

Figure 5 The fetal gene program is activated in right and left ventricles of $D s g 2^{M T}$ mice after disease onset. The diagrams show the quantitative RT-PCR results obtained for mRNA isolated from left and right ventricles. The data are given as fold change in comparison to the wild-type controls (dotted lines). Detailed data are provided in Table 2. Note that Nppb (A and B), Myh7 ( $\mathbf{C}$ and $\mathbf{D})$, and $\mathbf{A c t a 1}$ ( $\mathbf{E}$ and $\mathbf{F}$ ) gene expression are much more increased in the right than in the left ventricle. Furthermore, the increase in $\mathrm{Nppb}$ and Myh7 mRNA expression occurs earlier in the right ventricle than in the left ventricle. The decrease in Atp2a2 (G and $\mathbf{H}$ ) and phospholamban (Pln) mRNA (I and $\mathbf{J}$ ) occurs at the disease onset. Pln mRNA returns to wild-type expression levels by the age of 11 to 14 weeks. However, in the right ventricle, the reduced Atp2a2 mRNA expression continues throughout disease progression. Data are presented as Tukey's whisker plots.

G

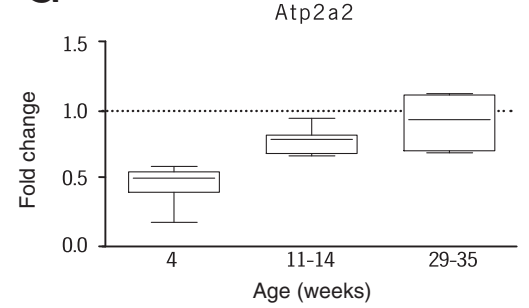

$\mathbf{J}$

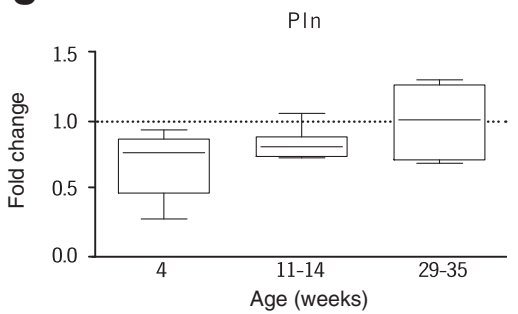

onset ( 4 weeks), at the end of the acute phase (11 to 14 weeks), and during the chronic phase (29 to 35 weeks). The mRNA level of the cardiac stress marker Nppb was significantly up-regulated in both ventricles of $D s g 2^{M T}$ mice compared to the wild-type mice. Nppb mRNA expression was preferentially elevated in the right ventricle throughout all disease phases (Figure 5B). Myh7 mRNA, another component of the fetal gene program, was up-regulated in both ventricles. In the right ventricle, the mRNA expression was strongly up-regulated shortly after disease onset and was maintained at high levels, whereas the highest increase of Myh7 mRNA was observed in the left ventricle between 12 weeks and 29 to 35 weeks in $D s g 2^{M T}$ mice. Skeletal muscle actin (Acta1), a marker of pathological hypertrophy, continuously increased over time in both ventricles of $D s g 2^{M T}$ mice.

To study if the increase of Myh7 and Nppb mRNA expression leads to altered protein expression, protein samples of right and left ventricles were subjected to immunoblot analysis (Figure 6 and Supplemental Figure S4). Myh7 protein expression was increased in both ventricles of $D s g 2^{M T}$ mice. However, the amount of $\mathrm{Nppb}$ protein remained unchanged in left and right ventricular samples of $D s g 2^{M T}$ mice despite the upregulation of Nppb mRNA expression. However, we could show that the Nppb plasma levels were significantly elevated in adult $D s g 2^{M T}$ mice and $D s g 2^{c K O}$ mice, another AC mouse model ${ }^{29}$ (Supplemental Figure S5).

\section{mRNA Expression of Calcium-Handling Proteins Is} Decreased in a Chamber- and Disease Stage-Specific Manner

We studied the mRNA expression of phospholamban and Atp2a2, which are involved in $\mathrm{Ca}^{2+}$ ion transport into the 
Table 2 Hypertrophic Marker mRNA Expression in the Left and Right Ventricle of $D s g 2^{M T}$ Mice and $D s g 2^{W T}$ Control Mice

\begin{tabular}{|c|c|c|c|c|}
\hline \multirow[b]{2}{*}{ Variable } & \multicolumn{2}{|l|}{ Left ventricle } & \multicolumn{2}{|l|}{ Right ventricle } \\
\hline & $\overline{D s g 2^{W T}}$ & $D s g 2^{M T}$ & $\overline{D s g 2^{W T}}$ & $D s g 2^{M T}$ \\
\hline \multicolumn{5}{|l|}{ Nppb } \\
\hline 11-14 weeks & $0.73 \pm 0.28$ & $1.70 \pm 0.69^{*}$ & $0.13 \pm 0.03$ & $1.22 \pm 0.44^{* *}$ \\
\hline $29-35$ weeks & $1.06 \pm 0.65$ & $4.14 \pm 1.52^{*}$ & $0.27 \pm 0.14$ & $2.78 \pm 0.55^{* *}$ \\
\hline \multicolumn{5}{|l|}{ Myh7 } \\
\hline 29-35 weeks & $20.2 \pm 10.7$ & $329 \pm 154^{*}$ & $0.43 \pm 0.21$ & $11.11 \pm 6.5^{* *}$ \\
\hline \multicolumn{5}{|l|}{ Acta1 } \\
\hline 4 weeks & $0.72 \pm 0.42$ & $2.34 \pm 1.04^{*}$ & $0.24 \pm 0.11$ & $0.91 \pm 0.54^{* *}$ \\
\hline 11-14 weeks & $0.16 \pm 0.14$ & $2.85 \pm 1.91^{* *}$ & $0.13 \pm 0.12$ & $1.21 \pm 0.59 * *$ \\
\hline $29-35$ weeks & $0.33 \pm 0.12$ & $6.58 \pm 5.84^{* *}$ & $0.14 \pm 0.01$ & $4.80 \pm 3.70^{* *}$ \\
\hline \multicolumn{5}{|l|}{ Atp2a2 } \\
\hline \multicolumn{5}{|l|}{ Pln } \\
\hline 4 weeks & $1.22 \pm 0.08$ & $0.97 \pm 0.24$ & $1.31 \pm 0.14$ & $0.90 \pm 0.31 * *$ \\
\hline 11-14 weeks & $1.50 \pm 0.14$ & $1.57 \pm 0.14$ & $1.93 \pm 0.29$ & $1.60 \pm 0.21^{*}$ \\
\hline 29-35 weeks & $1.73 \pm 0.42$ & $1.92 \pm 0.33$ & $1.43 \pm 0.17$ & $1.42 \pm 0.40$ \\
\hline \multicolumn{5}{|l|}{ Rcan1 } \\
\hline 4 weeks & $15.8 \pm 14.76$ & $31.6 \pm 13.8$ & $5.35 \pm 2.7$ & $26.17 \pm 17.1$ \\
\hline 11-14 weeks & $50.2 \pm 13.3$ & $131.1 \pm 39.0^{* *}$ & $45.97 \pm 32.6$ & $132.7 \pm 53.7^{*}$ \\
\hline $29-35$ weeks & $6.99 \pm 7.45$ & $77.8 \pm 54.8^{* *}$ & $8.95 \pm 3.97$ & $106.1 \pm 38.6^{* *}$ \\
\hline
\end{tabular}

Values are given as means \pm SD in arbitrary units. The Mann-Whitney $U$ test was applied to compare mRNA expression between wild type and mutants at each time point in left and right ventricular samples. The mRNA expression was assessed in five $D s g 2^{W T}$ and six $D s g 2^{M T}$ mice aged 4 weeks and in five $D s g 2^{W T}$ and eight $D s g 2^{M T}$ mice aged 11 to 13 weeks. In 7- to 8-month-old mice, the mRNA expression was assessed in the ventricles of five $D s g 2^{W T}$ and five $D s g 2^{M T}$ mice. For analysis of left ventricular Myh7 and Nppb mRNA expression, only four Dsg2 ${ }^{M T}$ samples were available.

${ }^{*} P<0.05,{ }^{* *} P<0.01$.

${ }^{\dagger}$ One $D s g 2^{M T}$ animal without an overt right ventricular phenotype was removed from the statistical analysis.

Acta1, $\propto 1$ skeletal muscle actin; Atp2a2, sarcoplasmic reticulum $\mathrm{Ca}^{(2+)-}$ ATPase 2; Dsg2 ${ }^{M T}$, desmoglein 2 mutant; Dsg2 $2^{W T}$, desmoglein 2 wild type; Myh7, myosin heavy chain 7; Nppb, natriuretic peptide B; Pln, phospholamban; Rcan1, regulator of calcineurin 1.

sarcoplasmic reticulum. Down-regulation of Atp2a2 and phospholamban leads to reduced sarcoplasmic $\mathrm{Ca}^{2+}$ load, which is associated with systolic and diastolic dysfunction during heart failure. ${ }^{35}$ Both mRNAs were significantly reduced in the right ventricle on disease onset at 4 weeks (Figure 5, G-J, and Table 2). The lowered levels persisted throughout the acute phase of the disease until 11 to 14 weeks and remained reduced in the case of sarcoplasmic/ endoplasmic reticulum calcium ATPase 2 mRNA. In the left ventricle, a temporary down-regulation of sarcoplasmic/ endoplasmic reticulum calcium ATPase 2 mRNA was observed at the age of 4 and 11 to 14 weeks, whereas phospholamban mRNA expression did not vary. Taken together, our data provide evidence for perturbed calcium handling, which is more pronounced in the right ventricle.

\section{Nfat Signaling Pathway}

To study if calcineurin-Nfat signaling is involved in the observed cardiomyocyte hypertrophy, Nfatc1, Nfatc2, Nfatc3, and Nfatc4 mRNA expression was studied by in situ hybridization in $D s g 2^{W T}$ and $D s g 2^{M T}$ mice
(Figure 7, A-H). Nfatc1 mRNA was primarily located in interstitial cells and scar tissue and only occasionally in cardiomyocytes (Figure 7, A and E). Nfatc2 (Figure 7, B and F) and Nfatc3 (Figure 7, C and G) mRNAs were predominantly located in cardiomyocytes and to a lesser extent in noncardiomyocytes. Nfatc4 mRNA was primarily detected in interstitial cells of $D s g 2^{W T}$ hearts but not in $D s g 2^{M T}$ hearts (Figure 7, D and H).

Rcan1 expression was investigated next, because it is a specific target gene of calcineurin-Nfat signaling and a surrogate marker for the activation of Nfat signaling. ${ }^{36}$ Rcan $1 \mathrm{mRNA}$ expression was moderately up-regulated in both ventricles of 4- and 12-week-old mutants (Table 2 and Figure 7, I and J). In addition, a pronounced increase of Rcan1 mRNA expression was observed in both ventricles of $D s g 2^{M T}$ mice at 29 to 35 weeks (Mann-Whitney $U$ tests: both $P=0.0079$ ).

\section{Discussion}

We hereby report on selective right ventricular cardiomyocyte hypertrophy in the failing hearts of $\mathrm{AC}$ patients. 


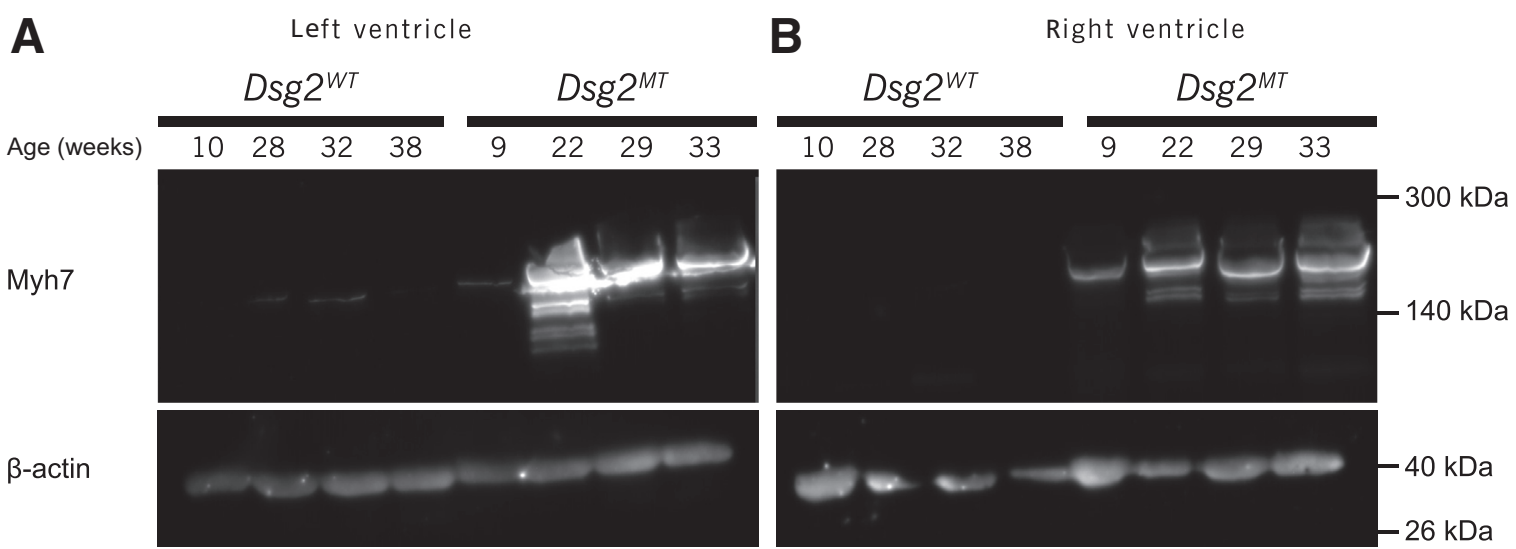

Figure 6 Myh7 protein expression is increased in both ventricles of $D s g 2^{M T}$ mice. Immunoblots were performed on left (A) and right ventricular (B) protein samples of $D s g 2^{M T}$ and $D s g 2^{W T}$ mice. Note that none or only small quantities of Myh7 protein are detected in wild-type hearts and that high levels of Myh7 protein (approximately $220 \mathrm{kDa}$ ) are detected in $D s g 2^{M T}$ hearts (top panels). The immunoblots were reacted with antibodies against $\beta$-actin after stripping (bottom panels). $n=4$ (A and $\mathbf{B}, D s g 2^{M T}$ mice and $D s g 2^{W T}$ mice).

We elucidated features of the hypertrophic response by analyzing molecular responses and by using a murine AC model to study cardiomyocyte hypertrophy during consecutive disease phases.

The hearts of AC patients with end-stage heart failure and the hearts of aged $D s g 2^{M T}$ mice (39 to 54 weeks) presented dilated right ventricles, thinning of the right ventricular wall, and fibrofatty or fibrotic replacement of the myocardium. Furthermore, patients and mutant mice develop right ventricular cardiomyocyte hypertrophy. The hypertrophy of right ventricular cardiomyocytes is shared with other diseases of the right ventricle, including pulmonary arterial hypertension, pulmonary stenosis, and some congenital heart diseases, ${ }^{26,37}$ which induce a right ventricular volume or pressure overload. The reexpression of genes coding for proteins of the maladaptive fetal gene program and the downregulation of Atp2a2 - a central component of the excitationcontraction coupling machinery-were found in conjunction with right ventricular hypertrophy in $\mathrm{AC}$ patients and in $D s g 2^{M T}$ mice. Most notably, the hearts of AC patients and the murine AC model displayed a predominant increase of $\mathrm{Nppb}$ mRNA expression within the right ventricle that is in line with the observed ventricular dilation and processes of adverse cardiac remodeling. Accordingly, Nppb may become a new marker for right ventricular dysfunction in AC patients, as already suggested for patients with pulmonary hypertension. ${ }^{20}$ Taken together, our findings show that many key features of maladaptive cardiac processes ${ }^{20,38,39}$ occur in human AC and murine AC models. We conclude that the selfamplifying nature of these reactive changes is highly relevant for the understanding of $\mathrm{AC}$ disease progression and therapeutic intervention.

$\mathrm{AC}$ pathologies are not restricted to the right ventricle but affect both ventricles in most patients. ${ }^{5,6}$ In accordance, cardiomyocyte hypertrophy and increased Nppb, Acta1, and Myh7 mRNA was also detected in the left ventricle of the $D s g 2^{M T}$ mice. However, the expression levels are considerably lower than in the right ventricle. In the human tissue samples, elevated MYH7 mRNA expression was detected in the left ventricle. MYH7 is known to modify cardiac contraction properties and to reduce energy consumption. ${ }^{40,41}$ These data correspond to the recently performed transcriptome analysis of end-stage $\mathrm{AC}$ ventricles ${ }^{42}$ and biventricular heart failure at end-stage disease. ${ }^{5}$ However, we did not find cardiomyocyte hypertrophy in the left ventricle of the human AC samples, whereas others have detected increased diameters of left ventricular cardiomyocytes in AC patients. ${ }^{43}$ The differences may reflect differences in disease manifestation, regional heterogeneities within the cardiac muscle, and the modus of cardiac tissue sampling. Examining the left anterior wall in the study of Basso and coworkers ${ }^{43}$ may have preselected for a region that is preferentially affected in AC patients and mouse models, ${ }^{6,29}$ whereas herein we studied myocardial samples that were intentionally taken from the healthyappearing myocardium of explanted hearts.

The unique advantage of murine models is the chance to examine pathological alterations at distinct stages of disease progression. Thus, phases of AC development can be distinguished in our $D s g 2^{M T}$ mice that are analogous to the disease phases in AC patients. ${ }^{8}$ Until 2 to 3 weeks after birth, $D s g 2^{M T}$ mice are inconspicuous, corresponding to the concealed preclinical phase in human AC. We find and describe, for the first time, that individual cardiomyocytes take up IgG during conversion to the overt/acute disease phenotype and interpret this as membrane fragility caused by $D s g 2$ mutation. This phase is characterized by right ventricular dilation and infarction-like events in one or both ventricles, followed by fibrosis. ${ }^{27,28}$ This phase is from 2 to 12 weeks and correlates to the phase of overt electrical and structural disorders in AC patients. Remarkably, other murine models of AC develop a phenotype at the same age. ${ }^{29,44,45}$ The subsequent chronic disease phase may result in biventricular heart failure in mouse and human. The 

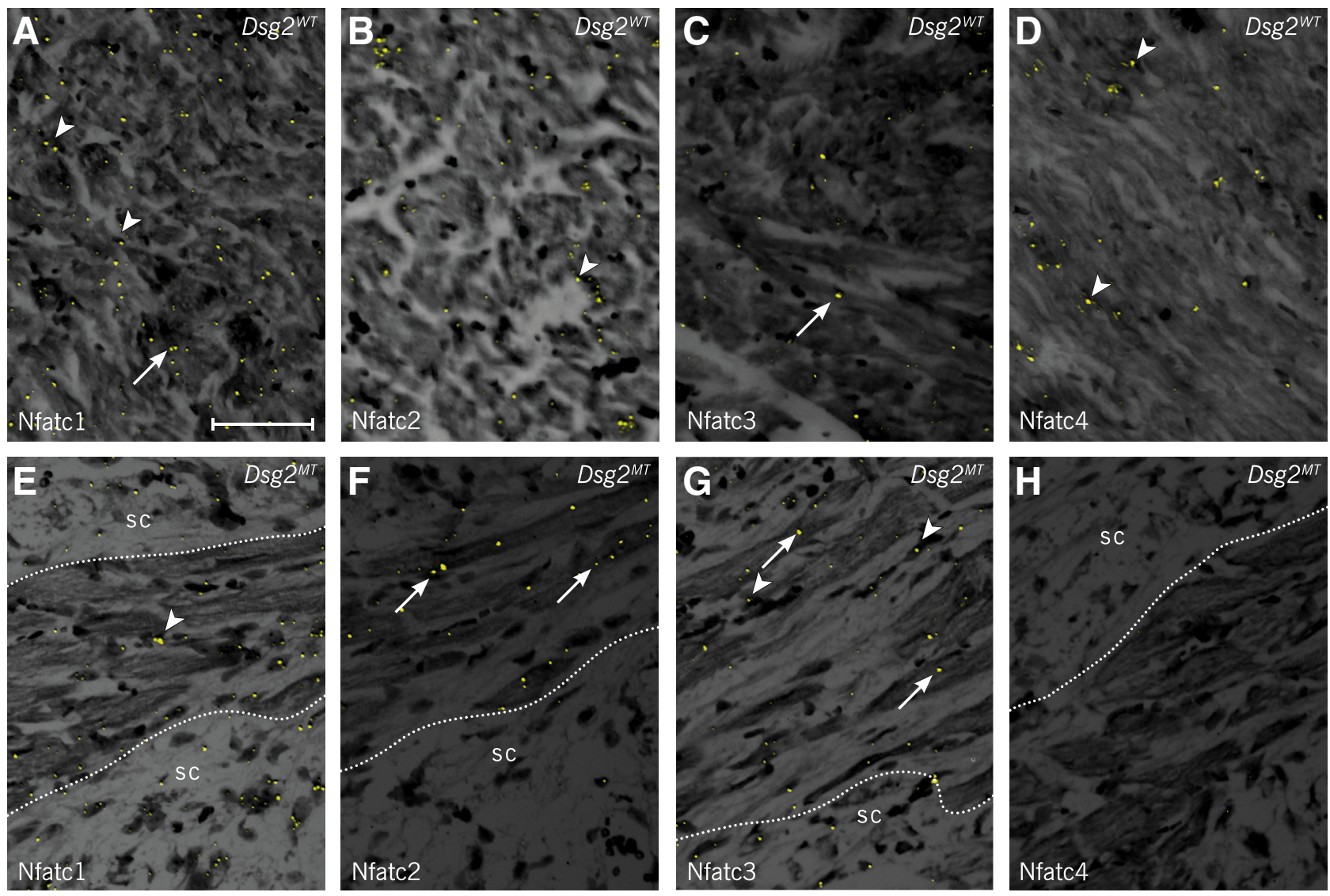

I

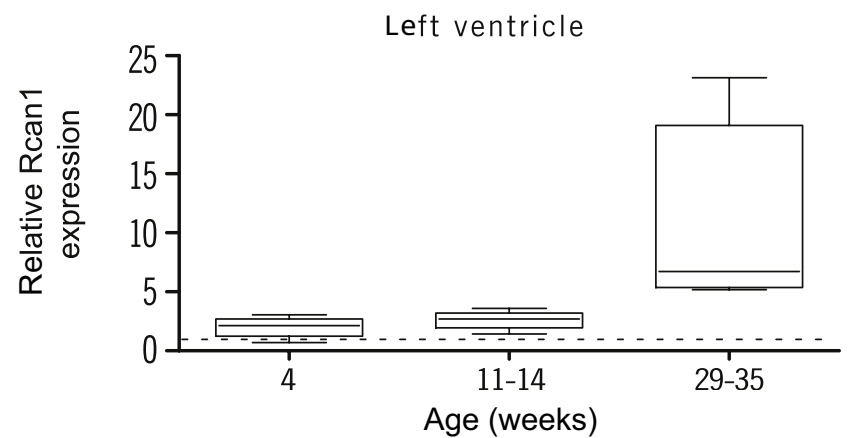

$\mathbf{J}$

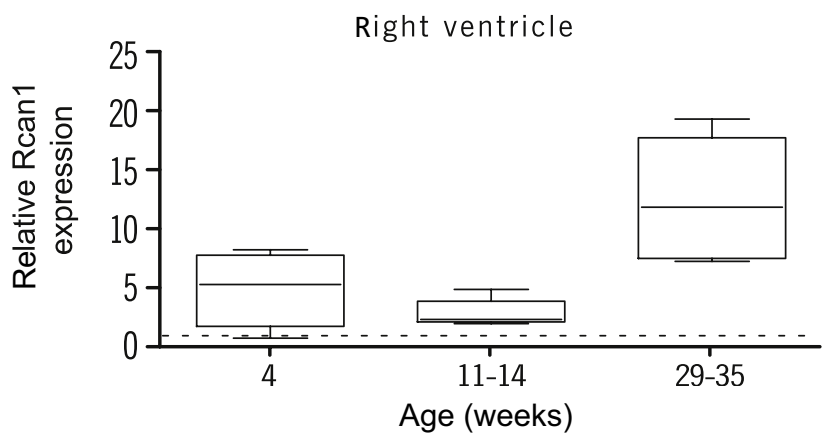

Figure 7 Nfatc2 and Nfatc3 mRNA are expressed in cardiomyocytes and the calcineurin-Nfat pathway is activated in Dsg2 ${ }^{M T}$ hearts. Nfatc1, Nfatc2, Nfatc3, and Nfatc4 mRNA expression was studied by in situ hybridization. A-H: Overlays composed of bright field images and fluorescence images of the mRNA detection signal (yellow dots) in $D s g 2^{W T}(\mathbf{A}-\mathbf{D})$ and $D s g 2^{M T}(\mathbf{E}-\mathbf{H})$ hearts. A and E: Nfatc1 mRNA is located in interstitial cells (arrowheads), occasionally in cardiomyocytes (arrow) and cells within the scar tissue (sc; demarcated by dotted lines). B, C, F, and G: Nfatc2 (B and F) and Nfatc3 (C and G) mRNA are predominantly located in cardiomyocytes (arrows) and to a lesser extent in noncardiomyocytes (arrowheads). Dotted lines in $\mathbf{F}$ and $\mathbf{G}$ indicate the border between cardiomyocytes and scar tissue. D and H: Nfatc4 mRNA is detected in interstitial cells (arrowheads) of Dsg2 ${ }^{W T}$ hearts (D). I and J: Quantitative RT-PCR analyses shows up-regulation of Rcan1 in both ventricles of $D s g 2^{M T}$ mice. The data are given as fold change in comparison to the wild-type controls (dashed lines). Rcan1 is a specific indicator of calcineurin-Nfat pathway activation. The moderate, but statistically significant, increase in 4- and 11- to 14-week-old $D s g 2^{M T}$ mice is followed by a more pronounced increase of Rcan1 expression at the age of 29 to 35 weeks during chronic disease progression (Table 2). Scale bar $=50 \mu \mathrm{m}(\mathbf{A}-\mathbf{H})$.

$D s g 2^{M T}$ mouse model recapitulates a juvenile-onset $\mathrm{AC}$ phenotype that is fully penetrant and characterized by infarction-like scarring. A similar phenotype is observed in adolescents with an early disease onset at 10 to 12 years of age. ${ }^{14,15}$ We exploited our mouse model to find out whether cardiomyocyte hypertrophy is an adaptive mechanism to the destabilizing effects of the mutant Dsg2 protein or a compensatory reaction after disease onset and chronic progression. Therefore, cardiomyocyte diameter and expression of genes associated with pathological hypertrophy were assessed at different disease stages. Larger cardiomyocyte diameters were first observed in $D s g 2^{M T}$ mice at an age of 6 
weeks, indicative of a compensatory response that is needed to overcome cardiomyocyte loss. Increased mRNA expression of genes belonging to the fetal cardiac gene program (Nppb, Myh7, and Actal) in conjunction with elevated Rcan1 mRNA expression ${ }^{36}$ and the localization of Nfatc2 and Nfatc 3 mRNA expression in cardiomyocytes of $D s g 2^{M T}$ mice indicates that pathological hypertrophy accompanies physiological cardiomyocyte growth in the AC mouse model. Furthermore, the more pronounced right ventricular up-regulation of these genes indicates that the right ventricle is more strongly affected by the mutant Dsg2 protein at disease onset.

During the second half of the acute/overt disease phase (ie, at the age of 6 to 13 weeks), cardiomyocyte diameter increased strongly in both ventricles of the $D s g 2^{M T}$ mice while myocardial scar maturation occurred. ${ }^{28}$ However, echocardiography revealed that cardiac parameters do not deviate substantially from age-matched wild-type mice and most mutants show no aggravation of left ventricular function in this phase. However, the significant reduction of the pulmonalis peak gradient in $D s g 2^{M T}$ mice at 13 weeks emphasizes the more adverse effects of Dsg2 mutation within the right ventricle. Overall cardiomyocyte hypertrophy compensates efficiently for cardiomyocyte loss in this disease phase, whereas cardiac decompensation sets in later on. ${ }^{27}$

Only one of seven $D s g 2^{M T}$ mice failed to compensate right ventricular function during the early disease phase. Because the underlying mechanisms of this failure are unknown, more detailed analyses of myocardial function and remodeling after lesion formation will help to define prognostic criteria for clinical outcome and to identify mutation carriers that are at risk for a rapid progression to heart failure.

On reaching adulthood at the age of 11 to 13 weeks, the final heart/body weight ratio and the definitive diameter of right ventricular cardiomyocytes are established in wild-type mice. ${ }^{46}$ At this age, the chronic AC phase starts in $D s g 2^{M T}$ mice; $95 \%$ of $D s g 2^{M T}$ animals do not develop new infarction-like lesions after reaching adulthood. Notably, the cardiac connective tissue is mature at this age and provides a stable scaffold for cardiomyocyte anchorage via costameres. ${ }^{47-49}$ We hypothesize that the maturation of costamer anchorage sites increases the stability of the desmin intermediate filament network. These lateral anchorage sites make the force-transmitting desmin network less dependent on the attachment to the intercalated disk that is likely compromised in the $D s g 2^{M T}$ mice and human AC patients. However, the maturation and stabilization of the connective tissue is not fully compensatory for dysfunctional mutant desmoglein 2 because the diameter of right ventricular cardiomyocyte is continuously increasing during the chronic disease phase. Disease progression and acceleration of pathological hypertrophy are also indicated by an agedependent increase of Rcan1, Acta1, Nppb, and Myh7 mRNA and Myh7 protein expression. We expect that the hypertrophy of right ventricular cardiomyocytes initiated in the acute phase leads to right ventricular ischemia, cardiomyocyte dysfunction, and death in a vicious cycle accelerating the pathological hypertrophy of the remaining cardiomyocytes during the chronic disease phase. Finally, these pathological processes culminate in right-sided heart failure.

\section{Acknowledgment}

We thank Adelina Baleanu-Curaj for performing echocardiography; Bärbel Bonn, Christine Eherer, Sabine Eisner, Marina Lürkens-Weber, and Claudia Schmitz for excellent technical assistance; and Adam Breitscheidel for graphical design.

M.G., C.A.K., and R.E.L. designed the study; M.G., Mu.G., S.K., S.S., E.A.L., and C.A.K. performed animal experiments and analyzed murine samples; M.G., A.K., and H.M. acquired and analyzed human samples; M.G., Mu.G., A.K., S.S., and C.A.K. performed statistical analysis; C.A.K., M.G., S.S., and R.E.L. prepared the manuscript; all authors approved the submitted and published versions of manuscripts.

\section{Supplemental Data}

Supplemental material for this article can be found at http://dx.doi.org/10.1016/j.ajpath.2016.12.018.

\section{References}

1. Basso C, Bauce B, Corrado D, Thiene G: Pathophysiology of arrhythmogenic cardiomyopathy. Nat Rev Cardiol 2012, 9: $223-233$

2. Awad MM, Calkins H, Judge DP: Mechanisms of disease: molecular genetics of arrhythmogenic right ventricular dysplasia/cardiomyopathy. Nat Clin Pract Cardiovasc Med 2008, 5:258-267

3. Pinamonti B, Brun F, Mestroni L, Sinagra G: Arrhythmogenic right ventricular cardiomyopathy: from genetics to diagnostic and therapeutic challenges. World J Cardiol 2014, 6:1234-1244

4. Thiene G, Corrado D, Basso C: Arrhythmogenic right ventricular cardiomyopathy/dysplasia. Orphanet J Rare Dis 2007, 2:45

5. Corrado D, Basso C, Thiene G, McKenna WJ, Davies MJ, Fontaliran F, Nava A, Silvestri F, Blomstrom-Lundqvist C, Wlodarska EK, Fontaine G, Camerini F: Spectrum of clinicopathologic manifestations of arrhythmogenic right ventricular cardiomyopathy/dysplasia: a multicenter study. J Am Coll Cardiol 1997, 30:1512-1520

6. Te Riele AS, James CA, Philips B, Rastegar N, Bhonsale A, Groeneweg JA, Murray B, Tichnell C, Judge DP, Van Der Heijden JF, Cramer MJ, Velthuis BK, Bluemke DA, Zimmerman SL, Kamel IR, Hauer RN, Calkins H, Tandri H: Mutation-positive arrhythmogenic right ventricular dysplasia/cardiomyopathy: the triangle of dysplasia displaced. J Cardiovasc Electrophysiol 2013, 24: $1311-1320$

7. Campuzano O, Alcalde M, Berne P, Castro V, Guzzo G, Iglesias A, Alonso-Pulpon L, Garcia-Pavia P, Brugada J, Brugada R: Genetic testing of candidate genes in arrhythmogenic right ventricular cardiomyopathy/dysplasia. Eur J Med Genet 2012, 55:225-234 
8. Turrini P, Basso C, Daliento L, Nava A, Thiene G: Is arrhythmogenic right ventricular cardiomyopathy a paediatric problem too? Images Paediatr Cardiol 2001, 3:18-37

9. Quarta G, Muir A, Pantazis A, Syrris P, Gehmlich K, Garcia-Pavia P, Ward D, Sen-Chowdhry S, Elliott PM, McKenna WJ: Familial evaluation in arrhythmogenic right ventricular cardiomyopathy: impact of genetics and revised task force criteria. Circulation 2011, 123: 2701-2709

10. Corrado D, Basso C, Rizzoli G, Schiavon M, Thiene G: Does sports activity enhance the risk of sudden death in adolescents and young adults? J Am Coll Cardiol 2003, 42:1959-1963

11. Saberniak J, Hasselberg NE, Borgquist R, Platonov PG, Sarvari SI, Smith HJ, Ribe M, Holst AG, Edvardsen T, Haugaa KH: Vigorous physical activity impairs myocardial function in patients with arrhythmogenic right ventricular cardiomyopathy and in mutation positive family members. Eur J Heart Fail 2014, 16:1337-1344

12. Corrado D, Basso C, Nava A, Thiene G: Arrhythmogenic right ventricular cardiomyopathy: current diagnostic and management strategies. Cardiol Rev 2001, 9:259-265

13. Bauce B, Basso C, Rampazzo A, Beffagna G, Daliento L, Frigo G, Malacrida S, Settimo L, Danieli G, Thiene G, Nava A: Clinical profile of four families with arrhythmogenic right ventricular cardiomyopathy caused by dominant desmoplakin mutations. Eur Heart J 2005, 26: $1666-1675$

14. Bauce B, Rampazzo A, Basso C, Mazzotti E, Rigato I, Steriotis A, Beffagna G, Lorenzon A, De Bortoli M, Pilichou K, Marra MP, Corbetti F, Daliento L, Iliceto S, Corrado D, Thiene G, Nava A: Clinical phenotype and diagnosis of arrhythmogenic right ventricular cardiomyopathy in pediatric patients carrying desmosomal gene mutations. Heart Rhythm 2011, 8:1686-1695

15. Hamilton RM: Arrhythmogenic right ventricular cardiomyopathy. Pacing Clin Electrophysiol 2009, 32 Suppl 2:S44-S51

16. Umar S, Nadadur R, Iorga A, Amjedi M, Matori H, Eghbali M: Cardiac structural and hemodynamic changes associated with physiological heart hypertrophy of pregnancy are reversed postpartum. J Appl Physiol 2012, 113:1253-1259

17. George K, Whyte GP, Green DJ, Oxborough D, Shave RE, Gaze D, Somauroo J: The endurance athletes heart: acute stress and chronic adaptation. Br J Sports Med 2012, 46 Suppl 1:i29-i36

18. Parvari R, Levitas A: The mutations associated with dilated cardiomyopathy. Biochem Res Int 2012, 2012:639250

19. Seidman CE, Seidman JG: Identifying sarcomere gene mutations in hypertrophic cardiomyopathy: a personal history. Circ Res 2011, 108: 743-750

20. Haddad F, Doyle R, Murphy DJ, Hunt SA: Right ventricular function in cardiovascular disease, part II: pathophysiology, clinical importance, and management of right ventricular failure. Circulation 2008, 117: $1717-1731$

21. Diwan A, Dorn GW 2nd: Decompensation of cardiac hypertrophy: cellular mechanisms and novel therapeutic targets. Physiology 2007, 22:56-64

22. Grossman W, Paulus WJ: Myocardial stress and hypertrophy: a complex interface between biophysics and cardiac remodeling. J Clin Invest 2013, 123:3701-3703

23. Luedde M, Katus HA, Frey N: Novel molecular targets in the treatment of cardiac hypertrophy. Recent Pat Cardiovasc Drug Discov 2006, 1: $1-20$

24. Harvey PA, Leinwand LA: The cell biology of disease: cellular mechanisms of cardiomyopathy. J Cell Biol 2011, 194:355-365

25. Samak M, Fatullayev J, Sabashnikov A, Zeriouh M, Schmack B, Farag M, Popov AF, Dohmen PM, Choi YH, Wahlers T, Weymann A: Cardiac hypertrophy: an introduction to molecular and cellular basis. Med Sci Monit Basic Res 2016, 22:75-79

26. Ryan JJ, Archer SL: The right ventricle in pulmonary arterial hypertension: disorders of metabolism, angiogenesis and adrenergic signaling in right ventricular failure. Circ Res 2014, 115: $176-188$
27. Krusche CA, Holthofer B, Hofe V, van de Sandt AM, Eshkind L, Bockamp E, Merx MW, Kant S, Windoffer R, Leube RE: Desmoglein 2 mutant mice develop cardiac fibrosis and dilation. Basic Res Cardiol 2011, 106:617-633

28. Kant S, Krull P, Eisner S, Leube RE, Krusche CA: Histological and ultrastructural abnormalities in murine desmoglein 2-mutant hearts. Cell Tissue Res 2012, 348:249-259

29. Kant S, Holthofer B, Magin TM, Krusche CA, Leube RE: Desmoglein 2-dependent arrhythmogenic cardiomyopathy is caused by a loss of adhesive function. Circ Cardiovasc Genet 2015, 8:553-563

30. Kant S, Krusche C, Gaertner A, Milting H, Leube RE: Loss of plakoglobin immunoreactivity in intercalated discs in arrhythmogenic right ventricular cardiomyopathy: protein mislocalization versus epitope masking. Cardiovasc Res 2016, 109:260-271

31. Straub V, Rafael JA, Chamberlain JS, Campbell KP: Animal models for muscular dystrophy show different patterns of sarcolemmal disruption. J Cell Biol 1997, 139:375-385

32. Liehn EA, Kanzler I, Konschalla S, Kroh A, Simsekyilmaz S, Sonmez TT, Bucala R, Bernhagen J, Weber C: Compartmentalized protective and detrimental effects of endogenous macrophage migration-inhibitory factor mediated by CXCR2 in a mouse model of myocardial ischemia/reperfusion. Arterioscler Thromb Vasc Biol 2013, $33: 2180-2186$

33. Zaugg CE, Buser PT: When calcium turns arrhythmogenic: intracellular calcium handling during the development of hypertrophy and heart failure. Croat Med J 2001, 42:24-32

34. Flurkey K, Currer JM, Harrison DE: The Mouse in Aging Research. ed 2. Burlington, MA, Elsevier, 2007

35. Bers DM, Eisner DA, Valdivia HH: Sarcoplasmic reticulum Ca2+ and heart failure: roles of diastolic leak and Ca2 + transport. Circ Res 2003, 93:487-490

36. Yang J, Rothermel B, Vega RB, Frey N, McKinsey TA, Olson EN, Bassel-Duby R, Williams RS: Independent signals control expression of the calcineurin inhibitory proteins MCIP1 and MCIP2 in striated muscles. Circ Res 2000, 87:E61-E68

37. Mitsuno M, Nakano S, Shimazaki Y, Taniguchi K, Kawamoto T, Kobayashi J, Matsuda H, Kawashima Y: Fate of right ventricular hypertrophy in tetralogy of Fallot after corrective surgery. Am J Cardiol 1993, 72:694-698

38. Kehat I, Molkentin JD: Molecular pathways underlying cardiac remodeling during pathophysiological stimulation. Circulation 2010, 122:2727-2735

39. Altin SE, Schulze PC: Metabolism of the right ventricle and the response to hypertrophy and failure. Prog Cardiovasc Dis 2012, 55: 229-233

40. Lowes BD, Minobe W, Abraham WT, Rizeq MN, Bohlmeyer TJ, Quaife RA, Roden RL, Dutcher DL, Robertson AD, Voelkel NF, Badesch DB, Groves BM, Gilbert EM, Bristow MR: Changes in gene expression in the intact human heart: downregulation of alpha-myosin heavy chain in hypertrophied, failing ventricular myocardium. J Clin Invest 1997, 100:2315-2324

41. Krenz M, Sanbe A, Bouyer-Dalloz F, Gulick J, Klevitsky R, Hewett TE, Osinska HE, Lorenz JN, Brosseau C, Federico A, Alpert NR, Warshaw DM, Perryman MB, Helmke SM, Robbins J: Analysis of myosin heavy chain functionality in the heart. J Biol Chem 2003, 278:17466-17474

42. Gaertner A, Schwientek P, Ellinghaus P, Summer H, Golz S, Kassner A, Schulz U, Gummert J, Milting H: Myocardial transcriptome analysis of human arrhythmogenic right ventricular cardiomyopathy. Physiol Genomics 2012, 44:99-109

43. Basso C, Ronco F, Marcus F, Abudureheman A, Rizzo S, Frigo AC, Bauce B, Maddalena F, Nava A, Corrado D, Grigoletto F, Thiene G: Quantitative assessment of endomyocardial biopsy in arrhythmogenic right ventricular cardiomyopathy/dysplasia: an in vitro validation of diagnostic criteria. Eur Heart J 2008, 29:2760-2771

44. Pilichou K, Remme CA, Basso C, Campian ME, Rizzo S, Barnett P, Scicluna BP, Bauce B, van den Hoff MJ, de Bakker JM, Tan HL, 
Valente M, Nava A, Wilde AA, Moorman AF, Thiene G, Bezzina CR Myocyte necrosis underlies progressive myocardial dystrophy in mouse dsg2-related arrhythmogenic right ventricular cardiomyopathy. J Exp Med 2009, 206:1787-1802

45. Mavroidis M, Capetanaki Y: Extensive induction of important mediators of fibrosis and dystrophic calcification in desmin-deficient cardiomyopathy. Am J Pathol 2002, 160:943-952

46. Zhou YQ, Foster FS, Parkes R, Adamson SL: Developmental changes in left and right ventricular diastolic filling patterns in mice. Am J Physiol Heart Circ Physiol 2003, 285:H1563-H1575
47. Capetanaki Y, Bloch RJ, Kouloumenta A, Mavroidis M, Psarras S: Muscle intermediate filaments and their links to membranes and membranous organelles. Exp Cell Res 2007, 313:2063-2076

48. Konieczny P, Fuchs P, Reipert S, Kunz WS, Zeold A, Fischer I, Paulin D, Schroder R, Wiche G: Myofiber integrity depends on desmin network targeting to Z-disks and costameres via distinct plectin isoforms. J Cell Biol 2008, 181:667-681

49. Hoshijima M: Mechanical stress-strain sensors embedded in cardiac cytoskeleton: z disk, titin, and associated structures. Am J Physiol Heart Circ Physiol 2006, 290:H1313-H1325 